CENTRE for ECONOMIC

$P$ E R F O R M A N C E

CEP Discussion Paper No 799

June 2007

\title{
Volatility, Labor Market Flexibility, and the Pattern of Comparative Advantage
}

Alejandro Cuñat and Marc J. Melitz 


\begin{abstract}
This paper studies the link between volatility, labor market flexibility, and international trade. International differences in labor market regulations affect how firms can adjust to idiosyncratic shocks. These institutional differences interact with sector specific differences in volatility (the variance of the firm-specific shocks in a sector) to generate a new source of comparative advantage. Other things equal, countries with more flexible labor markets specialize in sectors with higher volatility. Empirical evidence for a large sample of countries strongly supports this theory: the exports of countries with more flexible labor markets are biased towards high-volatility sectors. We show how differences in labor market institutions can be parsimoniously integrated into the workhorse model of Ricardian comparative advantage of Dornbush, Fisher and Samuelson (1977). We also show how our model can be extended to multiple factors of production.
\end{abstract}

Keywords: comparative advantage

JEL Classification: F1

This paper was produced as part of the Centre's Programme. The Centre for Economic Performance is financed by the Economic and Social Research Council.

\title{
Acknowledgements
}

We are grateful to Pol Antràs, Gordon Hanson, Peter Neary, Barbara Petrongolo, Steve Redding, Tony Venables, Jaume Ventura, and seminar participants in Alicante, Banco de España, Bocconi, Cambridge, ERWIT 2006, Harvard, LSE, NBER, Oxford, Pompeu Fabra, Princeton, Valencia, the AEA 2006 Meeting, and the EEA 2006 Meeting for helpful discussions and suggestions. Kalina Manova, Martin Stewart, and Rob Varady provided superb research assistance. All errors remain ours. Cuñat gratefully acknowledges financial support from CICYT (SEC 2002-0026). Melitz thanks the International Economics Section at Princeton University for its hospitality while this paper was written.

Alejandro Cuñat is an Associate of the Globalisation Programme at the Centre for Economic Performance, London School of Economics. He is also a Lecturer in the Department of Economics, University of Essex. Marc J. Melitz is an Associate Professor in the Department of Economics \& Woodrow Wilson School at Princeton University, USA.

Published by

Centre for Economic Performance

London School of Economics and Political Science

Houghton Street

London WC2A 2AE

All rights reserved. No part of this publication may be reproduced, stored in a retrieval system or transmitted in any form or by any means without the prior permission in writing of the publisher nor be issued to the public or circulated in any form other than that in which it is published.

Requests for permission to reproduce any article or part of the Working Paper should be sent to the editor at the above address.

(C) A. Cuñat and M. J. Melitz, submitted 2007

ISBN 9780853281757 


\section{Introduction}

Comparative advantage is usually attributed to international differences in production capabilities stricto senso. The Ricardian model, for example, stresses the importance of technology for explaining why countries trade, whereas the Heckscher-Ohlin model emphasizes international differences in relative factor endowments. But institutional differences can give way to comparative advantage, too, even when technologies and relative factor endowments are identical across countries. In particular, this paper studies the role of labor market flexibility as a source of comparative advantage.

Cross-country differences in labor market flexibility - as with other measures of institutional differences - are correlated with country income levels. Nevertheless, substantial differences in labor market flexibility persist within groups of countries with similar income levels. Within the OECD, for example, North-America, the British Isles and Oceania have much more flexible labor markets than most of continental Europe. Table 1 illustrates these differences within income groups using an index of labor market flexibility constructed by the World Bank. ${ }^{1}$ These institutional differences are associated with important cross-country differences in the flows of workers between employment and unemployment and, more importantly for our purposes, across jobs. Table 2, taken from Blanchard and Portugal (2001), compares job flows in the US, a country with a very flexible labor market, and Portugal, a country with a very rigid labor market. ${ }^{2}$ Although the American and Portuguese unemployment rates were similar during the early 90s, the Portuguese labor market exhibited much smaller flows of workers across different jobs. This finding is echoed in the OECD Employment Outlook (1999, chart 2.3) covering the 1990s, which shows a significant negative correlation across OECD countries between employment protection and job turnover rates. ${ }^{3}$

Worker flows vary importantly also across industries. Table 3, taken from Davis et al. (1997), displays average annual excess job reallocation rates (as a percentage of employment) by four-

\footnotetext{
${ }^{1}$ We discuss this index in detail in Section 4.

${ }^{2}$ Job creation at time $t$ equals employment gains summed over all plants that expand or start up between $t-1$ and $t$. Job destruction at time $t$ equals employment losses summed over all plants that contract or shut down between $t-1$ and $t$. Net employment growth equals the job creation rate minus the job destruction rate. Job reallocation at time $t$ is the sum of job creation and job destruction. Excess job reallocation equals the difference between job reallocation and the absolute value of net employment change.

${ }^{3}$ Bertola and Rogerson (1997) argue that additional institutional differences across countries - such as those generating wage compression - may counteract the effects of differences in employment protection and generate much smaller differences in the observed job reallocation rates across countries. In a different context (across regions in a country), Aghion et al. (2006) also highlight the important effects of differences in labor market institutions within India. They find that the growth effects of product market liberalization depend on differences in labor market regulation across states.
} 
digit (US SIC) manufacturing industry in the US. Excess job reallocation reflects simultaneous job creation and destruction within industries. It represents the "excess" portion of job reallocation over and above the amount required to accommodate net industry employment changes. Table 3 shows that the within-industry reallocation process exhibits a remarkable degree of cross-industry variation. Clearly, this variation cannot be attributed to differences in labor market regulation. We interpret this cross-industry variation as reflecting differences in the needed adjustments, at the firm-level, to idiosyncratic demand and productivity shocks: a higher within-industry dispersion of shocks entails a larger response in the within-industry reallocation of employment between firms.

We formalize a theory of comparative advantage in this context. For simplicity, we frame our insights within a one-factor model of trade between two countries with different labor market institutions (a 'flexible' and 'rigid' economy). These differences interact with industry-level differences in the dispersion of firm-level shocks to generate industry-level differences in relative productivity, and hence a 'Ricardian' source of comparative advantage. Again for simplicity, we do not model any technological differences between countries. Thus, in the absence of shocks, differences in labor market flexibility are irrelevant. There is then no source of comparative advantage, and no motive for trade. However, in the presence of firm-level shocks, the country with flexible labor markets can reallocate labor across firms more easily - leading to higher industry average productivity levels relative to the country with rigid labor markets. This productivity difference is then magnified by the dispersion of the within-industry shocks, which we refer to as industry volatility. The latter thus interacts with the institutional labor market differences to induce a pattern of comparative advantage across industries.

We also extend our model to incorporate a second factor, capital, whose reallocation across firms is not affected by the labor market institutions. Provided that this reallocation of capital across firms is subject to the same degree of rigidity in both countries, then the pattern of comparative advantage driven by industry volatility becomes more muted for capital intensive industries. In other words, rigid countries face less of a comparative disadvantage in capital intensive industries - holding industry volatility constant. Thus our model also explains how capital intensity can affect comparative advantage based on differences in labor market institutions - separately from the standard Hecksher-Ohlin effect via interactions with a country's capital abundance.

Besides these implications on comparative advantage, our model also yields interesting insights on the relationship between trade and unemployment in countries that suffer from important rigidities in their labor markets: trade with a flexible country imposes a trade-off between the wage rate 
(relative to that of the flexible economy) and its employment level. As the rigid economy's relative wage rises, foreign competition shrinks the range of sectors with a comparative advantage, and labor demand falls. This trade-off worsens with increases in labor market rigidity and with across-the-board (cross-industry) increases in volatility, as both of these phenomena enhance the flexible economy's competitiveness relative to the rigid economy.

We then empirically test the predictions of our model on the observed pattern of comparative advantage for a large sample of countries, using country-level export data at a detailed level of sector disaggregation (hundreds of sectors). ${ }^{4}$ We thus test whether countries with relatively more flexible labor markets concentrate their exports relatively more intensively in sectors with higher volatility. We also test the additional prediction of our model that capital intensity reduces this effect of volatility for countries with relatively more rigid labor markets. Naturally, we also control for other determinants of comparative advantage such as the interactions between country-level factor abundance and sector-level factor intensities. We use two distinct estimation approaches towards these goals. The first approach, in the spirit of Romalis (2004), uses the full cross-section of commodity exports across countries and sectors to test for interaction effects between the countrylevel and sector-level characteristics that jointly determine comparative advantage. ${ }^{5}$ Recognizing some important limitations (both theoretical and empirical) associated with this method, we also use a second more robust approach based on a country-level analysis. Both approaches strongly confirm our theoretical results.

The potential links between labor markets and comparative advantage have received an increasing level of attention in the recent trade literature. Saint-Paul (1997) analyzes the links between firing costs and international specialization according to the life-cycle of goods: countries with flexible labor markets exhibit a comparative advantage in 'new' industries subject to higher aggregate demand volatility (relative to more 'mature' industries). Haaland and Wooton (forthcoming) also focus on differences in firing costs across countries, and examine their implications for the location of multinational affiliates. Davidson et al. (1999) present an equilibrium unemployment model in which the country with a more efficient search technology has a comparative advantage in the good produced in high-unemployment/high-vacancy sectors. This is due to the differences in prices required to induce factors to search for matches in sectors with different break-up rates. Galdón (2002) shows that labor market rigidities can also affect specialization through long-term

\footnotetext{
${ }^{4}$ Data on value added by industry, such as UNIDO, provide much less finer levels of disaggregation.

${ }^{5}$ There is also a substantial earlier literature, starting with the work of Baldwin $(1971,1979)$, that examined the relationship between the structure of commodity exports and patterns of factor abundance.
} 
unemployment, which reduces the skills workers may need in 'new-economy' sectors. In the current paper, we focus on a relatively more tractable theoretical framework that lends itself to more direct empirical testing. In particular, we highlight the role of firm-level volatility, which can be measured across sectors, in shaping the pattern of comparative advantage. ${ }^{6}$

Our paper is also related to a growing literature that studies the effects of international differences in institutions on trade patterns. Levchenko (2004) shows that the quality of institutions (e.g., property rights, the quality of contract enforcement, shareholder protection) affects both trade flows and the distribution of the gains from trade between rich and poor countries. Costinot (2005) and Nunn (2005) extend models of trade with imperfect contracts, highlighting a link between country institutions (linked to contract enforcement) and the pattern of comparative advantage across sectors with different technological characteristics (which affect the sector's reliance on contract enforcement, such as the complexity of production or the need for relation-specific investments by workers). Finally, our work is also related to a number of papers that study the relationship between international trade and labor market outcomes in the presence of labor market rigidities. See, among others, the classic contributions by Brecher (1974a, 1974b), followed by the more recent contributions of Matusz (1996), Davis (1998a, 1998b), and Brügemann (2003).

The rest of the paper is structured as follows. Section 2 formalizes the paper's basic insights in a one-factor model. Section 3 extends the model's implications for comparative advantage to a two-factor setup. In section 4, we present the empirical evidence. Section 5 concludes. An appendix discusses some analytical details.

\section{The Model}

There are two countries, denoted by $c=F, H$. Each country is endowed with $\bar{L}$ units of labor, which are supplied inelastically (for any positive wage) and internationally immobile. Preferences are identical across countries. Agents maximize utility over a Cobb-Douglas aggregate $Q$ of a continuum of final goods $q(i)$, indexed by $i$ :

$$
Q \equiv \exp \left\{\int_{0}^{1} \ln q(i) d i\right\}
$$

\footnotetext{
${ }^{6}$ Koren and Tenreyro (2005) and di Giovanni and Levchenko (2006) also study the relationship between industry volatility and specialization, but do not relate it to international differences in labor market institutions.
} 
In each industry $i$, the final good is produced using a continuum of intermediate goods $y(i, z)$ according to the technology

$$
y(i)=\left[\int_{0}^{1} y(i, z)^{\frac{\varepsilon-1}{\varepsilon}} d z\right]^{\frac{\varepsilon}{\varepsilon-1}},
$$

where $y(i)$ denotes production of the final good $i$. We assume that these intermediate goods are gross substitutes: $\varepsilon>1$ (and thus that the intermediate goods used to produce a given final good are less differentiated than the final goods across industries). Each intermediate good is produced with labor only:

$$
y(i, z)=e^{\pi} L(i, z)
$$

where $\pi$ is a stochastic term. Within each industry, the $\pi^{\prime}$ s are iid draws from a common distribution $G_{i}($.$) , identical across countries, but different across industries, with mean 0$ and variance $\sigma^{2}(i)$. We refer to $\sigma^{2}(i)$ as industry $i$ 's 'volatility'. This formulation emphasizes shocks to intermediate good producers on the production side, but is nonetheless isomorphic to a formulation emphasizing demand shocks in equation (1). As a given realization of the productivity draw $\pi$ uniquely identifies an intermediate good producer $z$, we now switch to the use of this draw $\pi$ as our index for the intermediate goods.

We assume two different institutional scenarios. In country $F$, all markets are competitive, and the determination of all prices and the allocation of all resources take place after the realization of $\pi$. This captures the idea of a flexible economy that can costlessly reallocate resources towards their more efficient use. In country $H$, a wage is negotiated (e.g., by a labor union) and intermediate good producers then hire workers before the realization of $\pi$; no labor adjustment is allowed thereafter. This corresponds to the idea that rigidities prevent firms from adjusting to changing circumstances. We assume that the unemployed, if any, cannot bid down the economy-wide ex-ante specified wage, and that the intermediate good producer is contractually committed to paying the hired number of workers the negotiated wage (regardless of the realization of $\pi$ ). After the realization of $\pi$, production and commodity market clearing take place in a competitive setting, subject to the wage and employment restrictions. Intermediate goods producers anticipate this equilibrium, and adjust their contracted labor demand accordingly. Given ex-ante free entry into the intermediate goods sector, expected profits of the intermediate good producers are driven to zero.

Throughout the paper, we do not explicitly model the potential benefits derived from employment stability nor the determination of the negotiated wage. We assume that the level of labor market rigidity is pre-determined at the time the wage $w_{H}$ is chosen. We then model the poten- 
tial repercussions for aggregate employment $L_{H}$, potentially leading to unemployment whenever $L_{H}<\bar{L}$ (flexible wages ensure full employment in the flexible economy, $L_{F}=\bar{L}$ ). ${ }^{7}$ We thus focus our analysis on the repercussion of these choices for the pattern of comparative advantage. Although the institutional differences outlined above between the two countries are rather stark, we show in the appendix how our entire analysis can be extended to two countries with varying degrees of labor market flexibility. This degree of labor market flexibility can vary continuously between the extremes of the flexible and rigid economy described above.

\section{Autarky in the Flexible Country}

The zero-profit conditions for final good and intermediate good producers imply, respectively:

$$
\begin{aligned}
p_{F}(i) & =\left[\int_{-\infty}^{\infty} p_{F}(i, \pi)^{1-\varepsilon} d G_{i}(\pi)\right]^{\frac{1}{1-\varepsilon}}, \\
p_{F}(i, \pi) & =e^{-\pi} w_{F} .
\end{aligned}
$$

This yields

$$
p_{F}(i)=\frac{w_{F}}{\left[\int_{-\infty}^{\infty} e^{(\varepsilon-1) \pi} d G_{i}(\pi)\right]^{\frac{1}{\varepsilon-1}}},
$$

where $\tilde{\pi}_{F}(i) \equiv\left[\int_{-\infty}^{\infty} e^{(\varepsilon-1) \pi} d G_{i}(\pi)\right]^{\frac{1}{\varepsilon-1}}$ represents the productivity level in industry $i$. This is a weighted average of the productivity levels of the intermediate good producers $e^{\pi}$, where the weights are proportional to the intermediate good's cost share in the final good production. The corresponding goods and factor market clearing conditions close the model.

\section{Autarky in the Rigid Country}

Notice that the law of large numbers ensures there is no aggregate uncertainty. This implies that expectations on all variables before the realization of $\pi$ equal their ex-post counterparts except for, of course, the individual firm's realization. We assume that agents hold a diversified portfolio and that firms maximize expected profits. Given that all firms in industry $i$ are ex-ante identical,

\footnotetext{
${ }^{7}$ One can also think about the rigid economy without unemployment as an economy where institutions prohibit the enforcement of employment contracts contingent on the realization of the shock $\pi$. Following this re-interpretation, for both the flexible and rigid economy, employment contracts must be agreed upon before the realization of the shock $\pi$. The key difference between the two economies is that such contracts in the flexible economy can be made contingent upon the future realization of the shock. This setup obviates the need to appeal to any wage setting institution in the rigid economy. The equilibrium in the rigid economy is then the competitive outcome contingent on the contractual incompleteness.
} 
$L_{H}(i, z)=L_{H}(i)$ for all $z$. Ex-ante zero-profit conditions and market clearing imply:

$$
\begin{aligned}
p_{H}(i) & =\left[\int_{-\infty}^{\infty} p_{H}(i, \pi)^{1-\varepsilon} d G_{i}(\pi)\right]^{\frac{1}{1-\varepsilon}}, \\
w_{H} L_{H}(i) & =\int_{-\infty}^{\infty} p_{H}(i, \pi) y_{H}(i, \pi) d G_{i}(\pi), \\
e^{\pi} L_{H}(i) & =\left[\frac{p_{H}(i, \pi)}{p_{H}(i)}\right]^{-\varepsilon} y_{H}(i) .
\end{aligned}
$$

Equation (3) sets the price of final good $i$ equal to its unit cost; equation (4) equates the labor cost of an intermediate good producer in industry $i$ with expected revenue (hence ex-ante zero profits for those producers); equation (5) enforces market clearing for intermediate goods in industry $i .^{8}$ These equations yield

$$
p_{H}(i)=\frac{w_{H}}{\left[\int_{-\infty}^{\infty} e^{\frac{(\varepsilon-1)}{\varepsilon} \pi} d G_{i}(\pi)\right]^{\frac{\varepsilon}{\varepsilon-1}}}
$$

where $\tilde{\pi}_{H}(i) \equiv\left[\int_{-\infty}^{\infty} e^{\frac{(\varepsilon-1)}{\varepsilon} \pi} d G_{i}(\pi)\right]^{\frac{\varepsilon}{\varepsilon-1}}$ represents the productivity level in industry $i$ for the rigid economy.

As with the productivity $\tilde{\pi}_{F}(i)$ in the flexible economy, this productivity is a weighted average of the productivity levels of the intermediate good producers. Although the distribution of these intermediate good productivity levels are identical in both countries (for each sector $i$ ), the productivity averages are different as the cost shares of the intermediate goods in final good production systematically vary across countries. Final good producers in the flexible country can take full advantage of the dispersion of productivity levels among intermediate good producers by optimally shifting their expenditures towards the more productive ones (with lower prices). This reallocation process is constrained by the labor market rigidities in the other country. This, in turn, confers an absolute advantage to the flexible economy across all sectors: $\tilde{\pi}_{F}(i) \geq \tilde{\pi}_{H}(i) \forall i$, where this inequality is strict whenever $G_{i}(\pi)$ is non-degenerate (and there are idiosyncratic productivity shocks). ${ }^{9}$

\footnotetext{
${ }^{8}$ Despite the labor market rigidity, the labor market clears under autarky: the law of large numbers implies zero profits at the industry level, $p_{H}(i) y_{H}(i)=w_{H} L_{H}(i) \forall i$. The labor market clearing condition then yields $\int_{0}^{1} L_{H}(i) d i=\int_{0}^{1} \frac{p_{H}(i) y_{H}(i)}{w_{H}} d i=L_{H}$, and holds for $L_{H}=\bar{L}$. The choice of $w_{H}$ proportionally shifts all prices $p_{H}(i)$ and has no effect on employment.

${ }^{9} \mathrm{This}$ is a direct application of Jensen's inequality.
} 


\section{Parametrization of Productivity Draws}

In order to simplify some of the ensuing analysis in an open-economy equilibrium, we parametrize the productivity draws to the normal distribution, thus assuming that $\pi(i) \sim N\left[0, \sigma^{2}(i)\right]$. Without loss of generality we assume that the industries are ranked in order of increasing volatility such that $\sigma(i)$ is increasing in $i$. We further assume that $\sigma(i)$ is differentiable and positive. The average industry productivity levels can then be written as

$$
\begin{aligned}
& \tilde{\pi}_{F}(i)=\exp \left\{(\varepsilon-1) \frac{\sigma^{2}(i)}{2}\right\}, \\
& \tilde{\pi}_{H}(i)=\exp \left\{\frac{(\varepsilon-1)}{\varepsilon} \frac{\sigma^{2}(i)}{2}\right\} .
\end{aligned}
$$

\section{Free Trade}

We assume free trade in final goods, but assume that intermediate goods remain non-traded. Following, Dornbusch et al. (1977), we define the productivity differential

$$
A(i) \equiv \frac{\tilde{\pi}_{H}(i)}{\tilde{\pi}_{F}(i)}=\exp \left\{-\frac{(\varepsilon-1)^{2}}{2 \varepsilon} \sigma^{2}(i)\right\}
$$

As previously mentioned, labor market flexibility confers an absolute advantage to the flexible economy: $A(i) \leq 1$. However, the labor market institutions also interact with industry volatility to engender a pattern of Ricardian comparative advantage: $A(i)$ is decreasing in industry volatility $\sigma^{2}(i)$. The productivity differential between the flexible and rigid economy increases with industry volatility. This confers a comparative advantage to the flexible economy in high-volatility industries.

The free-trade equilibrium is characterized by a wage ratio $w_{H} / w_{F}$ and a marginal commodity $\bar{\imath}$. For $i \leq \bar{\imath}, w_{H} / w_{F} \leq A(i)$, and $\operatorname{good} i$ is produced by country $H$. For $i>\bar{\imath}, w_{H} / w_{F}>A(i)$, and good $i$ is produced by country $F$. In equilibrium, the value of world consumption must equal the value of world output, which equals world labor income: $P\left(Q_{F}+Q_{H}\right)=w_{F} L_{F}+w_{H} L_{H}$, where $P$ denotes the price of $Q$. The value of country $H$ 's output, equal to country $H$ 's labor income, must also equal what the world spends on it. ${ }^{10}$ If $H$ produces goods in the range $[0, i]$, then $w_{H} L_{H}=i P\left(Q_{F}+Q_{H}\right)=i\left(w_{F} L_{F}+w_{H} L_{H}\right)$. Therefore we can write

$$
\frac{w_{H} L_{H}}{w_{F} L_{F}}=\frac{i}{1-i} \equiv B(i)
$$

\footnotetext{
${ }^{10}$ This condition is also equivalent to balanced trade.
} 
where $B^{\prime}(i)>0$. In closing the model, we distinguish between two cases, which depend on the chosen level of $w_{H}$ relative to $w_{F}$, and its consequences for unemployment in the rigid economy. We normalize $w_{F}=1$, and thus emphasize that the chosen wage level $w_{H}$ in the rigid economy is an indicator of worker purchasing power relative to the flexible economy. Recall that full employment prevails in the flexible economy, ensuring that $L_{F}=\bar{L}$ is exogenously given.

\section{Full Employment in the Rigid Country}

We first assume that $w_{H}$ is chosen in order to generate full employment, hence $L_{H}=\bar{L}$. In this case, the intersection of $A(i)$ and $B(i)$ determines the free-trade equilibrium. (See Figure 1.) An overall increase in volatility such that $\sigma^{\prime}(i)>\sigma(i), \forall i$, causes $A(i)$ to shift down while $B(i)$ remains unchanged. (See again Figure 1.) This leads to a decrease in the range of final goods produced in $H$ (i.e. a lower $\bar{\imath}$ ) and a lower relative wage $w_{H}$. Such an overall increase in volatility (as has been empirically measured in the last half century for the US) thus alters the pattern of comparative advantage, inducing relative welfare gains for the economy with flexible labor markets.

\section{Unemployment in the Rigid Country}

We now assume that $w_{H}$ is chosen above its market-clearing level. Recall that country $F$ 's labor market clears, so that $L_{F}=\bar{L}$. In this case, the condition $w_{H}=A(\bar{\imath})$ determines the equilibrium specialization pattern: $\bar{\imath}=\bar{\imath}\left(w_{H}\right)$. Notice that, since $A(\cdot)$ is negatively sloped, $\partial \bar{\imath} / \partial w_{H}<0$. Goods market clearing requires $w_{H} L_{H} / \bar{L}=\bar{\imath}\left(w_{H}\right) /\left[1-\bar{\imath}\left(w_{H}\right)\right]=B\left(w_{H}\right)$, where $B(\cdot)$ depends negatively on $w_{H}$. It is easy to see that country $H$ 's employment level depends negatively on $w_{H}$, too: $L_{H}=\bar{L} B\left(w_{H}\right) / w_{H}, \partial L_{H} / \partial w_{H}<0$. Hence, free trade with a flexible economy imposes a trade-off between the relative wage rate and unemployment in the rigid economy: as $w_{H}$ rises, the range of sectors in which country $H$ is competitive shrinks due to foreign competition, and labor demand falls.

This implies that an increase in volatility across all industries will worsen the trade-off between the relative wage $w_{H}$ and unemployment $\left(\bar{L}-L_{H}\right)$. To see this more precisely, assume that volatility can vary in all industries by a proportional factor $\psi>0$. That is, $\sigma^{\prime}(i)=\psi \sigma(i)$, where $\sigma^{\prime}(i)$ denotes the new standard deviation of productivity shocks. In this case, $w_{H}=A(\bar{l}, \psi)$, $\bar{\imath}=\bar{\imath}\left(w_{H}, \psi\right), L_{H}=\bar{L} B\left(w_{H}, \psi\right) / w_{H}, \partial L_{H} / \partial w_{H}<0$, and $\partial L_{H} / \partial \psi<0$. An overall increase in volatility thus leads to higher unemployment levels at a given relative wage $w_{H}$, or to decreases in the latter at a given employment level $L_{H}$. In the appendix we allow for a continuous index 
of labor market flexibility $\lambda$ in both countries, where a higher $\lambda$ represents a more flexible labor market. We show that increases in $\lambda_{F}-\lambda_{H}$ have effects equivalent to those of an increase in $\sigma$.

A word of caution is needed here. We stress that these comparative statics involve the relative wage $w_{H} / w_{F}$, and not the real wage $w_{H} / P$ in the rigid economy. The standard gains from trade also apply to this model, so that trade improves welfare in both countries, and hence the real wage $w_{H} / P$ in the rigid economy. Overall increases in volatility also induce aggregate welfare gains as they induce absolute increases in productivity levels. Our analysis emphasizes that these gains are biased towards the flexible economy, improving relative welfare therein.

\section{Two Factors}

We now develop a two-factor version of our model. ${ }^{11}$ We assume that countries are endowed with both capital and labor, and that industries differ in terms of capital intensity as well as volatility. The Cobb-Douglas aggregate good $Q$ is now defined according to

$$
Q \equiv \exp \left\{\int_{0}^{1} \int_{0}^{1} \ln q(i, j) d i d j\right\}
$$

where an industry is now characterized by a pair $(i, j)$ representing an index for both volatility $(i)$ and capital intensity $(j)$. The final good in each industry is still produced from a C.E.S. continuum of intermediate goods indexed by $z$ :

$$
y(i, j)=\left[\int_{0}^{1} y(i, j, z)^{\frac{\varepsilon-1}{\varepsilon}} d z\right]^{\frac{\varepsilon}{\varepsilon-1}},
$$

Intermediate goods are now produced with both capital and labor, according to

$$
y(i, j, z)=e^{\pi}\left[\frac{K(i, j, z)}{\alpha(j)}\right]^{\alpha(j)}\left[\frac{L(i, j, z)}{1-\alpha(j)}\right]^{1-\alpha(j)},
$$

where $\alpha(j) \in[0,1]$ is the industry's cost share of capital and the index of capital intensity. As in the one-factor model, the $\pi^{\prime}$ s are iid draws from a common distribution, identical across countries, but different across industries. We maintain the Normal parametrization for the productivity draws $\pi(i) \sim N\left[0, \sigma^{2}(i)\right]$. Labor market flexibility varies across countries in the same way as above. We assume that in both countries, the rental rate and the allocation of capital to intermediate good

\footnotetext{
${ }^{11}$ Our discussion here focuses on comparative advantage. We do not address the issue of unemployment, as we do not make use of factor market clearing conditions in our empirical analysis.
} 
producers are determined prior to the realization of $\pi$; no adjustment is allowed thereafter. In other words, we assume that capital is a 'rigid' factor in both countries. In the appendix, we show that all the results we test empirically for capital intensity would also continue to hold when we extend the model to a third factor, which is flexible across countries. Additionally, similar results also hold for this flexible factor. Thus, the key differentiating aspect for any factor other than labor is that its degree of rigidity is independent of differences in labor market rigidities across countries.

\section{Autarky in the Flexible Country}

In the appendix, we show that

$$
p_{F}(i, j)=\frac{r_{F}^{\alpha(j)} w_{F}^{1-\alpha(j)}}{\tilde{\pi}_{F}(i, j)},
$$

where the numerator is the standard Cobb-Douglas unit cost function. The industry average productivity level $\tilde{\pi}_{F}(i, j)$ is now given by

$$
\tilde{\pi}_{F}(i, j)=\exp \left\{\frac{\varepsilon-1}{1+\alpha(j)(\varepsilon-1)} \frac{\sigma^{2}(i)}{2}\right\}
$$

Notice that for $\alpha(j)=0, \tilde{\pi}_{F}(i, j)$ is identical to the previously derived $\tilde{\pi}_{F}(i)$ for the one-factor case. As the capital intensity increases, the ability of the final good producer to reallocate expenditures across intermediate goods is reduced (since capital is assumed to be rigid), leading to decreases in average productivity.

\section{Autarky in the Rigid Country}

Since factor prices and the allocation of both factors are determined before the realization of $\pi$, all intermediate good producers in an industry hire the same amount of capital and labor. The following analysis is an immediate extension of the one-factor rigid-country case:

$$
p_{H}(i, j)=\frac{r_{H}^{\alpha(j)} w_{H}^{1-\alpha(j)}}{\tilde{\pi}_{H}(i, j)},
$$

where average productivity $\tilde{\pi}_{H}(i, j)$ is now given by

$$
\tilde{\pi}_{H}(i, j)=\exp \left\{\frac{(\varepsilon-1)}{\varepsilon} \frac{\sigma^{2}(i)}{2}\right\} .
$$




\section{The Pattern of Comparative Advantage}

Without loss of generality, we assume that $\alpha(j)$ is an increasing and differentiable function of $j$. As in the one-factor case, we can define

$$
A(i, j) \equiv \frac{\tilde{\pi}_{H}(i, j)}{\tilde{\pi}_{F}(i, j)}=\exp \left\{-\frac{(\varepsilon-1)^{2}}{2 \varepsilon} \frac{1-\alpha(j)}{1+\alpha(j)(\varepsilon-1)} \sigma^{2}(i)\right\}
$$

as the ratio of productivity levels for a given industry across the two countries. This ratio highlights, once again, the absolute productivity advantage of the flexible economy in all sectors: $A(i, j)<$ $1, \forall i, j$. It also highlights how the pattern of comparative advantage varies with both volatility and capital intensity. $\partial A(i, j) / \partial i<0$ as in the one factor case: the productivity advantage is larger in more volatile industries. However, $\partial A(i, j) / \partial j>0$ : holding volatility constant, this productivity advantage is reduced in relatively more capital intensive industries. This is intuitive, as a larger capital share reduces the ability of the flexible economy to take full advantage of the dispersion in productivity levels. ${ }^{12}$ Needless to say, international factor price differences will also affect the pattern of comparative advantage. In our empirical work we separately control for these effects in order to isolate the effect of labor market flexibility on country specialization patterns via relative productivity differences. ${ }^{13}$

\section{Empirical Evidence}

\section{Data Construction and Description}

\section{Country-Level Data}

The key new country-level variable needed to test the predictions of our model is a measure of labor market rigidity across countries. Following the work of Botero et al. (2004), the World Bank has collected such measures, which capture different dimensions of the rigidity of employment laws across countries. ${ }^{14}$ These measures cover three broad employment areas: hiring costs, firing costs, and restrictions on changing the number of working hours. The World Bank also produces a combined summary index for each country (weighing the measures in all areas). This variable is

\footnotetext{
${ }^{12}$ As was previously noted, these last two comparative statics also hold for a third factor whose use is flexible across countries.

${ }^{13}$ In a separate technical appendix, we also show how one can theoretically analyze the joint effects of relative productivity (induced by labor market flexibility) and relative factor prices on the determination of the pattern of comparative advantage around a symmetric world equilibrium.

${ }^{14}$ This data, along with more detailed descriptions on its collection, is available online at http://www.doingbusiness.org/ExploreTopics/HiringFiringWorkers/
} 
coded on a 100-point integer scale indicating increasing levels of rigidity. We subtract this variable from 100 to produce a measure of flexibility and use this as our main country labor market flexibility index, FLEX_c. (See Table 1.) Unfortunately, historical data is not available, so we only have data for 2004. We will thus use the most recent data available from other sources to combine with this data.

Our remaining country level variables come from the Penn World Tables (PWT 6.0 and 6.1). We measure capital abundance (K_c) as the physical capital stock per capita. ${ }^{15}$ Human skill abundance (S_c) is calculated as the average years of schooling in the total population from Barro and Lee (2000). ${ }^{16}$ We also record data on real GDP (GDP_c) and real GDP per capita (GDPPC_c). All of the above measures are available over time, up to 1996 (when data for some countries in our sample are then no longer available). We thus use the data for 1996 for all countries (and the Barro-Lee data for 1995). The GDP and capital stock variables are measured in 1996 international dollars.

When we combine these 2 sources of country-level data, we are left with 81 countries. However, we will most often restrict our analysis to countries with available GDP per capita levels above $\$ 2,000$, leaving us with 61 countries. ${ }^{17}$ Other countries are excluded from this sample because the Penn World Tables do not have capital stock data for them (most notably, for Germany and other countries that have recently merged or split-up). ${ }^{18}$ However, we will include these countries in our additional robustness checks with our country-level analysis.

\section{Sector-Level Data}

Our empirical approach also requires a measure of firm-level volatility across sectors, as well as standard measures of factor intensities in production. This type of data is not available across our large sample of countries (at the needed detailed level of sectoral disaggregation), so we rely

\footnotetext{
${ }^{15}$ We use capital stock per capita, as opposed to per worker, for consistency with the definition of human capital. Although the correlation between the two measures is very high (.98), we also found that the capital abundance measure per capita had slightly more explanatory power than its usual measure per worker. Needless to say, this difference is barely noticeable for our main results.

${ }^{16}$ We also tried alternate measures of skill abundance, such as the fraction of workers that completed high school, or attained higher education (from Barro and Lee (2000)). These measures were clearly dominated by the one based on average years of schooling in explaining the pattern of comparative advantage across skill intensive sectors.

${ }^{17}$ The excluded countries are Benin, Bangladesh, Central African Republic, Cameroon, Congo, Ghana, Kenya, Mali, Mozambique, Malawi, Niger, Nicaragua, Nepal, Pakistan, Rwanda, Senegal, Sierra Leone, Togo, Uganda, and Zambia. United Arab Emirates, Bosnia and Herzegovina, and Kiribati are excluded due to missing GDP per capita data.

${ }^{18}$ The full list of excluded countries with GDP per capita above $\$ 2,000$ falling in this category are: Albania, Armenia, Azerbaijan, Bulgaria, Belarus, Czech Republic, Germany, Estonia, Georgia, Guinea, Guyana, Kazakhstan, Kyrgyzstan, Kuwait, Lebanon, Lithuania, Latvia, Morocco, Republic of Moldova, Macedonia, Oman, Russian Federation, Saudi Arabia, Slovakia, Slovenia, Ukraine, Uzbekistan.
} 
on the commonly used assumption that the ranking of measures do not vary across countries. We therefore use a reference country, the US, to measure all these needed sector characteristics. Factor intensity data in manufacturing are available over time from the NBER-CES Manufacturing Industry Database at the 4-digit US SIC level (459 industrial sectors). For each sector, we measure capital intensity (K_s) as capital per worker and skill intensity (S_s) as the ratio of non-production wages to total wages. We have experimented with other formulations for these factor intensities, such as those based on the 3-factor model in Romalis (2004), but found that the latter had much less explanatory power for the pattern of comparative advantage than our preferred measures. ${ }^{19}$ Again, we use the most recent data available, but also average out the data across the latest 5 available years, 1992-1996, in order to smooth out any small yearly fluctuations (especially for very small sectors). ${ }^{20}$ All measures are also aggregated to the 3 -digit SIC level (140 sectors).

Concerning firm-level volatility, the appendix shows there is a direct relationship between the standard deviation of firm-level shocks, $\sigma(i)$, and the standard deviation of the growth rate of firm sales (VOL_s). ${ }^{21}$ We measure differences in firm-level volatility across sectors using COMPUSTAT data from Standard \& Poor's. This data covers all publicly traded firms in the US, and contains yearly sales and employment data since 1980 (the past 24 years). We use the standard deviation of the annual growth rate of firm sales (measured as year-differenced log sales) as our benchmark measure of firm volatility. ${ }^{22}$ Thus, our volatility measure is purged of any trend growth rate in firms sales. COMPUSTAT records the 4-digit SIC classification for each firm, although some firms are only classified into a 3-digit, and in rarer instances, into a 2-digit SIC classifications. As expected, the distribution of firms across sectors is highly skewed. In order to obtain data on the largest possible number of sectors, we include in our analysis all firms with at least 5 years of data (using all the data going back to 1980) and all sectors with at least 10 firms. ${ }^{23}$ However, we do not include any observation where the absolute value of the growth rate is above $300 \%$. This leaves us with

\footnotetext{
${ }^{19}$ Another commonly used measure of skill intensity is the ratio of non-production workers to total workers (whereas we use the ratio of the payments to these factors). These measures have a correlation coefficient of .94, and yield nearly identical results.

${ }^{20}$ These factor intensity measures are highly serially correlated (the average serial correlation is .99 for capital intensity and .97 for skill intensity), so this averaging does not substantially change any of our results.

${ }^{21}$ The appendix also shows that rewriting the model in terms of VOL_s does not alter the model's comparative statics discussed above.

${ }^{22}$ For robustness, we experimented with another measure of volatility based on firm productivity: the standard deviation of the annual growth rate of sales per worker. Both volatility measures are highly correlated across firms (.83 correlation ratio). We only report the results obtained with the volatility measure based on sales, as those obtained with the volatility measure based on sales per worker were very similar.

${ }^{23}$ We have also experimented with a more stringent requirement of 10 years of data and 20 firms per sector. Our main results remain unchanged.
} 


\section{5,216 firms in our sample.}

We compute the sector-level measure as the average of the firm-level volatility measures, weighted by the firm's average employment over time. This yields volatility measures for 94 of the 4594 digit sectors and 88 of the 140 3-digit sectors. (Table 4 provides some descriptive statistics for this variable.) We use volatility measures at the 2-digit level for the remaining sectors (there are 20 such classifications, and there are always enough firms to compute volatility measures at this level). Often, in these cases, there is only one dominant 4-digit sector within this 2-digit classification. ${ }^{24}$ We construct both a 4-digit and a 3-digit level measure of volatility. Whenever a volatility measure is not available at the desired level of disaggregation, we use the measure from the next lower level of aggregation.

\section{Country-Sector Exports}

Instead of only measuring each country's exports into the US (as in Romalis (2004)), we follow the approach of Nunn (2005) and measure each country's aggregate exports across sectors. This country export data is available from the World Trade Flows Database (see Feenstra et al. (2005)) for the years 1962-2000 and is classified at the 4-digit SITC rev. 2 level. There are 768 distinct such sectors with recorded trade in the 1990s across all countries. Once we exclude non-manufacturing sectors, and concord the remaining sectors to the US SIC classification, we are left with 370 sectors. ${ }^{25}$ Again, we wish to use the most recent data available, but also want to smooth the effects of any year-toyear fluctuations in the distribution of exports across sectors (again, we are mostly concerned with smaller sectors where aggregate country exports can be more volatile). For this reason, we average exports over the last 10 years of available data, for 1991-2000. This yields our measure of aggregate exports, $X_{s c}$, across sectors and countries. We also aggregate this variable to the 3 -digit SIC level (134 distinct classifications are available).

\footnotetext{
${ }^{24}$ If COMPUSTAT only records a firm's sector at the 2- or 3-digit level, then we use that firm for the relevant classification. We also aggregate all firms with 4-digit level sector information into their respective 2- and 3-digit classifications.

${ }^{25}$ Since publicly available concordances from SITC rev.2 to US SIC do not indicate proportions on how individual SITC codes should be allocated to separate SIC codes, we construct our own concordance. We use export data for the US, that is recorded at the Harmonized System (HS) level (roughly 15,000 product codes). For each HS code, both an SITC and an SIC code is listed. We aggregate up the value of US exports over all HS codes for the last 10 available data years (1991-2000) across distinct SITC and SIC pairs. For each SITC code, we record the percentage of US exports across distinct SIC codes. We then concord exports for all countries from SITC to SIC codes using these percentage allocations. In most cases, this percentage is very high, so our use of US trade as a benchmark cannot induce any serious biases. For $50 \%$ of SITC codes, the percentage assigned to one SIC code is above $98 \%$. For $75 \%$ of SITC codes, this percentage is above $76 \%$.
} 


\section{Pooled Country-Sector Analysis}

Our baseline specification is:

$$
\begin{gathered}
\log X_{s c}=\beta_{0}+\beta_{v f}\left(\mathrm{VOL} \_\mathrm{s} * \log \mathrm{FLEX} \_\mathrm{c}\right)+\beta_{k f}\left(\log \mathrm{K} \_\mathrm{s} * \log \mathrm{FLEX} \_\mathrm{c}\right)+ \\
+\beta_{k k}\left(\log \mathrm{K} \_\mathrm{s} * \log \mathrm{K} \_\mathrm{c}\right)+\beta_{s s}\left(\log \mathrm{S} \_\mathrm{s} * \log \mathrm{S} \_\mathrm{c}\right)+\chi_{s}+\chi_{c}+\varepsilon_{s c},
\end{gathered}
$$

where $\chi_{s}$ and $\chi_{c}$ are sector and country level fixed effects. Given these fixed effects, our specification is equivalent to one where exports are measured as a share or as a ratio relative to the exports of a given reference country. Similarly, the specification is also equivalent to one where the country characteristics are measured as differences relative to a reference country. All data measures (except for VOL_s) are entered in logs (VOL_s is a summary statistic of a logged variable).

Our model predicts $\beta_{v f}>0$ : countries with more flexible labor markets export relatively more in relatively more volatile sectors. ${ }^{26}$ Additionally, our model predicts $\beta_{k f}<0$ : after controlling for the effects of volatility across sectors, countries with less flexible labor markets export relatively more in relatively more capital intensive sectors (since the effect of volatility is relatively less severe as capital intensity increases). The similar traditional comparative advantage predictions, based on factor abundance and factor intensity, are $\beta_{k k}>0$ and $\beta_{s s}>0$. Since our volatility measure is not uniformly available at the 4-digit SIC level, we test these predictions using both the data at the 4-digit level and 3-digit level. To ensure that our results are not dominated by low-income countries, we also include specifications where we exclude all countries with GDP per capita below $\$ 5,000$ (leaving us with 42 countries with available capital stock data).

The results from the OLS regressions of equation (10) across the different data samples are listed in Table 5. We find strong confirmation both for the predictions of our model and the traditional forces of specialization according to comparative advantage. The table lists the standardized beta coefficients, which capture the effects of raising the independent variables by one standard deviation (measured in standard deviations of the dependent variable). The magnitude of the coefficient on the volatility-flexibility interaction is of the same magnitude, though higher, than those reported by Nunn (2005) and Levchenko (2004) for the effects of institutional quality on the pattern of

\footnotetext{
${ }^{26}$ This is a very 'demanding' interpretation of the theory, since the latter does not imply a monotonic relationship across sectors and countries in a multi-country world. For example, a country with mid-range labor market flexibility could concentrate its exports in sectors with mid-range volatility. This effect would not get picked up by our regression analysis, which is searching for differences in slopes, given a monotonic linear response of export shares across sectors for a country.
} 
comparative advantage. Table 5 shows that the level of sector disaggregation does not greatly influence the results, though the magnitude of the coefficients are a little higher at the more aggregated 3-digit level. We thus continue our analysis using only the 3-digit level data.

Since the regressions in Table 5 do not include observations where no exports are recorded for a given country, the results should be interpreted as capturing the pattern of comparative advantage for countries across all of its export sectors - and not the effect of comparative advantage on the country-level decision to export in particular sectors (which are likely affected by other additional sector and country characteristics). We maintain this interpretation throughout our analysis, but also provide an additional robustness check in Table 6, where the reported regressions have used all potential country-sector combinations: we add missing export observations with zero exports, then add 1 to all export values before taking logs. (Tobit specifications censored at zero yield extremely similar results to those reported in Table 6.) This table shows that all our results remain strongly significant, though the magnitude of most of the coefficients drops substantially (this effect is most pronounced for the skill intensity - skill abundance coefficient, whereas the capital intensity - capital abundance coefficient is mostly unaffected).

We next confirm that our results are not driven by other country and sector characteristics outside of our model. In recent work, Koren and Tenreyro (2005) have shown that increasing levels of economic development across countries are associated with a pattern of comparative advantage towards less volatile sectors - where this volatility is measured as the aggregate sector volatility of output per worker. We replicate their results by computing a similar measure of aggregate productivity volatility from the NBER-CES Manufacturing Productivity database. We measure the volatility of sector-level output per worker (VOLPROD_AGG_s) using the same methods as the firm-level volatility measures: taking the standard deviation of its annual growth rate. We then add an additional control for the interaction between this measure of aggregate productivity volatility and development (measured as the log of GDP per capita). The results are reported in the first 2 columns of Table 7. They show that a country's level of development is correlated with its pattern of comparative advantage across sectors with lower aggregate productivity volatility. This effect is very significant and important when the low-income countries, with GDP per capita between $\$ 2,000$ and $\$ 5,000$, are included in the sample (the results for this added regressor are also substantially stronger at the 4-digit level for countries above the $\$ 5,000$ GDP per capita threshold). Nonetheless, the table also shows that our main results on the effect of labor market flexibility on the pattern of comparative advantage remain unaffected. 
We next show that the driving force behind the effect of volatility on the pattern of comparative advantage operates at the firm-level and not at the sector-level. We construct a sector-level measure of sales volatility, VOL_AGG_s, following the same procedure as that outlined for aggregate productivity volatility (also using the NBER-CES Manufacturing data). We then interact this sector level variable with labor market flexibility and include it as an additional regressor. The results, reported in the third and fourth columns of Table 7, clearly show that this aggregate volatility has no measurable effect on the pattern of comparative advantage.

Lastly, we add two additional sets of controls. One set includes interactions of country factor abundance measures (K_c and $\mathrm{S}_{-} \mathrm{c}$ ) with sector volatility VOL_s. This controls for any other possible interactions between factor abundance (and their effects on factor prices) and sector level volatility. For example, Bernard, Redding, and Schott (forthcoming) show how there can be a possible interaction between comparative advantage (via differences in factor abundance) and volatility (via higher levels of simultaneous entry and exit due to a higher survival cutoff). The other set is comprised of interactions between the level of development (again, using GDP per capita) and all three sector-level measures, VOL_s, K_s, and S_s. The latter control for other country-level determinants driving the pattern of comparative advantage. This last set of results is reported in the last two columns of Table (7). The addition of the interactions with GDP per capita strongly affects the magnitude of the predictions for the standard sources of comparative advantage (capital and skill abundance interacted with that factor's intensity in production): these coefficients drop significantly in three out of the four specifications. ${ }^{27}$ Most importantly, however, the key coefficients of interest for labor market flexibility are not substantially affected by the additional controls; they retain their strong statistical significance.

\section{Country-Level Analysis}

We now address some potential limitations in the pooled country-sector analysis by moving to a country-level analysis. Our main concern is that the previous results do not adequately reflect the very skewed pattern of country exports across sectors - as they can be influenced by country-sector pairs with relatively very low exports. We are also concerned that our key measure of volatility is available at different levels of aggregation (representing different overall levels of economic activity). To address these concerns, we construct a country average level of volatility: for each country, sector

\footnotetext{
${ }^{27}$ The results further show that GDP per capita, rather than direct measures of skill abundance, captures relatively more of the variation across countries explaining specialization in skill-intensive sectors.
} 
level volatility is averaged using its export share as a weight. Specifically, average country volatility VOL_c is obtained as

$$
\mathrm{VOL}_{-} \mathrm{c}=\sum_{s} \frac{X_{s c}}{X_{c}} \mathrm{VOL} \_\mathrm{s} .
$$

Thus, countries with higher export shares in more volatile sectors will have higher levels of this volatility average. This average also naturally handles the skewness of the distribution of country level exports by assigning larger weights to more important sectors. We use the 4-digit measure of volatility, as the averaging also naturally handles the different levels of aggregation, by essentially splitting off sectors with available 4-digit volatility data into separate sectors, and keeping the other sectors grouped by their inherent level of disaggregation. We can thus test whether countries with more flexible labor markets have a comparative advantage in relatively more volatile sectors by examining the correlation across countries between VOL_c and FLEX_c. ${ }^{28}$

We control for the influence of other comparative advantage forces in two separate ways. By introducing other country-level controls in a regression of VOL_c on FLEX_c; and alternatively by first purging the sector volatility measure VOL_s of any correlation with other relevant sector characteristics, and then looking at the direct correlation between the country level average of this purged volatility measure (VOL_PURGED_c) and FLEX_c. Table 8 reports the results corresponding to the regression of the un-purged country volatility average (VOL_c) on labor market flexibility, also including additional country controls (GDPPC_c, S_c, and log(K_c)). ${ }^{29}$ Here, we add two additional sample groups of countries: one with a higher GDP per capita cutoff of $\$ 10,000$, and another including the full sample of available countries by weighting them using the log of real GDP. The results show the strong independent contribution of labor market flexibility on the pattern of comparative advantage - across all country sample groups.

Lastly, we turn to the second approach discussed above. We use all the previously used sector-level measures (K_s, S_s, VOL_AGG_s), as well as measures of the intensity of intermediate goods (material cost per worker) and energy use (energy spending per worker). We run an initial regression of VOL_s on all these sector level controls, and construct the residual as VOL_PURGED_s (its correlation coefficient with VOL_s is .93). Table 9 reports the correlation coefficients (which are also the standardized beta coefficients) between VOL_PURGED_c

\footnotetext{
${ }^{28}$ One other advantage of this country-level method is that, unlike in the pooled country-sector analysis above, it does not require a monotonic response in a country's share of exports across sectors to detect a pattern of comparative advantage.

${ }^{29}$ We introduce the capital stock per worker variable in logs, since it varies by an order of magnitude greater than for the other independent country-level variables. Entering this control in levels instead does not substantially change the results.
} 
and FLEX_c across all the country samples from Table 8, including an additional group of OECD countries (with membership in the 1990s). ${ }^{30}$ As the table results clearly show, there is a very strong correlation between country-level flexibility and this average volatility, across all sub-samples of countries: all correlation coefficients are significant well beyond the 1\% level. Figures 2-4 show the scatter plots for these relationships for different country samples.

\section{Concluding Remarks}

Comparative advantage can arise even when the genuine production capabilities (resources and technologies) of countries are identical, provided they differ in labor market institutions. Countries with more flexible labor markets should display a comparative advantage precisely where the ability to adjust is more important, that is, industries subject to high-variance shocks. The empirical evidence presented above supports the validity of this intuition for a large sample of countries: more flexible countries export relatively more in high volatility industries.

This result has some interesting implications. First, labor market reform is likely to have asymmetric effects across industries. Second, a rigid economy has an alternative to the liberalization of its labor market to improve its welfare: it can always liberalize trade and 'import flexibility' from a more flexible trading partner. Finally, an extension of the model might provide an additional explanation for the outsourcing phenomenon: production of intermediate goods may be relocated to more flexible labor markets in high-volatility industries.

\section{References}

[1] Aghion, P., R. Burgess, S.J. Redding, and F. Zilibotti (2006): "The Unequal Effects of Liberalization: Evidence from Dismantling the License Raj in India," NBER WP 12031.

[2] Baldwin, R.E. (1971): "Determinants of the Commodity Trade Structure of US Trade," American Economic Review, 61(1), pp. 147-159.

[3] Baldwin, R.E. (1979): "Determinants of Trade and Foreign Investment: Further Evidence," Review of Economics and Statistics, 61(1), pp. 40-48.

[4] Barro, R.J. and J.W. Lee (2000): "International Data on Educational Attainment Updates and Implications," NBER WP 7911.

[5] Bernard, A.B., S.J. Redding, and P.K. Schott (2006): "Comparative Advantage and Heterogeneous Firms," Review of Economic Studies, forthcoming.

\footnotetext{
${ }^{30}$ We can use this much smaller sample of countries since we are not losing any degrees of freedom with additional co-variates.
} 
[6] Bertola, G., and R. Rogerson (1997): "Institutions and Labor Reallocation," European Economic Review 41 (6), pp. 1147-71.

[7] Blanchard, O. and P. Portugal (2001): "What Hides behind an Unemployment Rate: Comparing Portuguese and US Labor Markets," American Economic Review, 91(1), pp. 187-207.

[8] Botero, J., S. Djankov, R. La Porta, F. López de Silanes, and A. Shleifer (2004): "The Regulation of Labor," Quarterly Journal of Economics, 119(4), pp. 1339-1382.

[9] Brecher, R.A. (1974a): "Minimum Wage Rates and the Pure Theory of International Trade," Quarterly Journal of Economics, 88(1), pp. 98-116.

[10] Brecher, R.A. (1974b): "Optimal Commercial Policy for a Minimum-Wage Economy," Journal of International Economics, 4(2), pp. 139-149.

[11] Broda, C., and D. E. Weinstein (2006): "Globalization and the Gains from Variety," Quarterly Journal of Economics 121(2), pp. 541-85.

[12] Brügemann, B. (2003): "Trade Integration and the Political Support for Labor Market Rigidity," manuscript, Yale.

[13] Costinot, A. (2005): "Contract Enforcement, Division of Labor, and the Pattern of Trade," manuscript, UCSD.

[14] Davidson, C., L. Martin, and S. Matusz (1999): "Trade and Search Generated Unemployment," Journal of International Economics, 48, pp. 271-299.

[15] Davis, D.R. (1998a): "Does European Unemployment Prop up American Wages? National Labor Markets and Global Trade," American Economic Review, 88(3), pp. 478-494.

[16] Davis, D.R. (1998b): “Technology, Unemployment, and Relative Wages in a Global Economy," European Economic Review, 42, pp. 1613-1633.

[17] Davis, S.J., J.C. Haltiwanger, and S. Schuh (1997): Job Creation and Destruction, MIT Press.

[18] di Giovanni, J. and A.A. Levchenko (2006): "The Risk Content of Exports," manuscript, IMF.

[19] Dornbusch, R., S. Fischer, and P.A. Samuelson (1977): "Comparative Advantage, Trade, and Payments in a Ricardian Model with a Continuum of Goods," American Economic Review, 67(5), pp. 823-839.

[20] Feenstra, R.C., R.E. Lipsey, H. Deng, A.C. Ma, and H. Mo (2005): "World Trade Flows," NBER WP 11040.

[21] Galdón-Sánchez, J.E. (2002): "Employment Protection Legislation and the IT-Sector in OECD Countries," Recherches Économiques de Louvain, 68(1-2), pp. 21-36.

[22] Haaland, J.I. and I. Wooton (2006): "Domestic Labour Markets and FDI," Review of International Economics, forthcoming.

[23] Koren, M. and S. Tenreyro (2005): "Volatility and Development," Quarterly Journal of Economics, forthcoming.

[24] Levchenko, A.A. (2004): "Institutional Quality and International Trade," IMF WP/04/231. 
[25] Matusz, S.J. (1996): "International Trade, the Division of Labor, and Unemployment" International Economic Review, 37(1), pp. 71-84.

[26] Nunn, Nathan (2005): "Relationship-Specificity, Incomplete Contracts, and the Pattern of Trade," Quarterly Journal of Economics, forthcoming.

[27] OECD Employment Outlook (1999): "Employment Protection and Labour Market Performance", Chapter 2, OECD.

[28] Romalis, J. (2004): "Factor Proportions and the Structure of Commodity Trade," American Economic Review, 94(1), pp. 67-97.

[29] Saint-Paul, G. (1997): "Is Labour Rigidity Harming Europe's Competitiveness? The Effect of Job Protection on the Pattern of Trade and Welfare," European Economic Review, 41, pp. 499-506. 
Table 1: Country Labor Market Flexibility Index, by GDP per Capita Cutoff $2,000<$ GDPPC_c $=5,000 \quad 5,000<$ GDPPC_c $=10,000 \quad$ GDPPC_c $>10,000$

\begin{tabular}{|c|c|c|c|c|c|}
\hline Name & FLEX_c & name2 & FLEX_c & name2 & $\overline{\text { FLEX_c }}$ \\
\hline Morocco* & 30 & $\overline{\text { Mexico }}$ & 28 & Spain & 31 \\
\hline Ukraine* & 36 & Brazil & 28 & France & 34 \\
\hline Guinea* & 41 & Paraguay & 41 & Greece & 34 \\
\hline Uzbekistan* & 42 & Venezuela & 44 & Portugal & 42 \\
\hline Indonesia & 43 & Turkey & 45 & Germany* & 45 \\
\hline Peru & 45 & Belarus* & 46 & Slovenia* & 47 \\
\hline Algeria & 45 & Tunisia & 46 & Argentina & 49 \\
\hline Moldova* & 46 & South Africa & 48 & Italy & 50 \\
\hline Egypt & 47 & Colombia & 49 & Finland & 56 \\
\hline El Salvador & 48 & Latvia* & 51 & Netherlands & 57 \\
\hline Ecuador & 49 & Estonia* & 56 & Sweden & 57 \\
\hline Georgia* & 51 & Thailand & 58 & Austria & 60 \\
\hline India & 52 & Lithuania* & 59 & Oman* & 65 \\
\hline Philippines & 59 & Hungary & 60 & Republic of Korea & 66 \\
\hline Bolivia & 60 & Iran & 60 & Israel & 67 \\
\hline Dominican Republic & 60 & Costa Rica & 65 & Norway & 70 \\
\hline Guatemala & 60 & Poland & 66 & Ireland & 71 \\
\hline Sri Lanka & 60 & Uruguay & 69 & Czech Republic* & 72 \\
\hline Kyrgyzstan* & 62 & Bulgaria* & 72 & Japan & 76 \\
\hline Azerbaijan* & 62 & Kazakhstan* & 73 & Belgium & 80 \\
\hline Macedonia* & 62 & Russian Federation* & 73 & United Kingdom & 80 \\
\hline Syria & 63 & Fiji & 79 & Kuwait* & 80 \\
\hline Armenia* & 64 & Chile & 81 & Switzerland & 83 \\
\hline Jordan & 66 & Slovakia* & 90 & Australia & 83 \\
\hline Honduras & 69 & Malaysia & 97 & Denmark & 83 \\
\hline China & 70 & & & Saudi Arabia* & 87 \\
\hline Albania* & 70 & & & New Zealand & 93 \\
\hline Lebanon* & 72 & & & Canada & 96 \\
\hline Zimbabwe & 76 & & & United States & 97 \\
\hline Papua New Guinea & 83 & & & Singapore & 100 \\
\hline Jamaica & 90 & & & Hong Kong & 100 \\
\hline
\end{tabular}

Notes: * Countries with missing data on physical or human capital abundance. 
Table 2: Job Reallocation: Comparing US and Portugal

Quarterly job creation and destruction, all manufacturing sectors

(Source: Blanchard and Portugal (2001))

Job Creation Job Destruction Job Reallocation

Portugal

(1991:1-1995:4)

US

(1972:2-1993:4)
4

6.8
3.9

7.3
7.9

14

Table 3: Variation in Job Reallocation Rates Across Sectors

Average annual excess job reallocation rates, US manufacturing sectors

(Source: Davis, Haltiwanger, and Schuh (1997))

Percentile

$1 \%$

$5 \%$

$10 \%$

$25 \%$

$50 \%$

$75 \%$

$90 \%$

$95 \%$

$99 \%$
Excess Job Reallocation

4.1

6.2

7.4

9.9

12.9

15.8

19.4

21.7

25.6

13.2

514 
Table 4: The Ten Least and Most Volatile Sectors at the 3-Digit SIC Level

\begin{tabular}{cccl} 
SIC-3 & VOL_s \# firms & Description \\
\hline 203 & 0.084 & 33 & Preserved Fruits \& Vegetables \\
386 & 0.096 & 42 & Photographic Equipment \& Supplies \\
285 & 0.097 & 16 & Paints \& Allied Products \\
271 & 0.100 & 24 & Newspapers \\
276 & 0.103 & 15 & Manifold Business Forms \\
358 & 0.103 & 52 & Refrigeration \& Service Machinery \\
267 & 0.105 & 48 & Misc. Converted Paper Products \\
342 & 0.105 & 24 & Cutlery, Handtools, \& Hardware \\
314 & 0.112 & 25 & Footwear, Except Rubber \\
327 & 0.115 & 25 & Concrete, Gypsum, \& Plaster Products
\end{tabular}

\begin{tabular}{cccl} 
SIC-3 & VOL_s \# firms & Description \\
\hline 333 & 0.236 & 20 & Primary Nonferrous Metals \\
302 & 0.247 & 10 & Rubber \& Plastics Footwear \\
355 & 0.255 & 104 & Special Industry Machinery \\
274 & 0.262 & 16 & Miscellaneous Publishing \\
332 & 0.263 & 13 & Iron \& Steel Foundries \\
346 & 0.265 & 20 & Metal Forgings \& Stampings \\
202 & 0.287 & 17 & Dairy Products \\
369 & 0.300 & 59 & Misc. Electrical Equipment \& Supplie \\
367 & 0.306 & 316 & Electronic Components \& Accessories \\
361 & 0.336 & 17 & Electric Distribution Equipment
\end{tabular}

Table 5: Pooled Regression - Baseline

\begin{tabular}{|c|c|c|c|c|}
\hline SIC aggregation & SIC-4 & SIC-3 & SIC-4 & SIC-3 \\
\hline GDPPC cutoff & 2000 & 2000 & 5000 & 5000 \\
\hline VOL_s * log FLEX_c & 0.300 & 0.298 & 0.356 & 0.382 \\
\hline & $(0.060) * * *$ & $(0.073) * * *$ & $(0.070) * * *$ & $(0.083) * * *$ \\
\hline $\log \mathrm{K} \_s * \log$ FLEX_c & $\begin{array}{l}-0.239 \\
(0.069) * * *\end{array}$ & $\begin{array}{l}-0.300 \\
(0.094) * * *\end{array}$ & $\begin{array}{l}-0.173 \\
(0.080) * *\end{array}$ & $\begin{array}{l}-0.223 \\
(0.114) *\end{array}$ \\
\hline $\log \mathrm{K} \_\mathrm{S} * \log \mathrm{K} \_\mathrm{c}$ & $\begin{array}{l}0.773 \\
(0.092) * * *\end{array}$ & $\begin{array}{l}1.055 \\
(0.119) * * *\end{array}$ & $\begin{array}{c}0.546 \\
(0.169) * * *\end{array}$ & $\begin{array}{c}1.057 \\
(0.232) * * *\end{array}$ \\
\hline $\log S \_s * \log S \_c$ & $\begin{array}{l}0.802 \\
(0.063) * * *\end{array}$ & $\begin{array}{l}0.961 \\
(0.091) * * *\end{array}$ & $\begin{array}{l}0.822 \\
(0.077) * * *\end{array}$ & 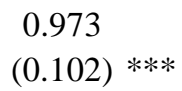 \\
\hline Observations & 13203 & 6513 & 9739 & 4675 \\
\hline R-squared & 0.7016 & 0.7481 & 0.6913 & 0.7472 \\
\hline
\end{tabular}

Notes: Beta coefficients are reported. Country and sector dummies suppressed. Heteroskedasticity robust standard errors in parentheses. ${ }^{*}$ significant at $10 \% ; * *$ significant at $5 \% ; * * *$ significant at $1 \%$ 
Table 6: Pooled Regression - Including Obsevations with No Exports

\begin{tabular}{lcccc}
\hline SIC aggregation & SIC-4 & SIC-3 & SIC-4 & SIC-3 \\
GDPPC cutoff & 2000 & 2000 & 5000 & 5000 \\
\hline VOL_s * log FLEX_c & 0.097 & 0.165 & 0.113 & 0.189 \\
& $(0.039) * *$ & $(0.059) * * *$ & $(0.038) * * *$ & $(0.060) * * *$ \\
log K_s * log FLEX_c & -0.168 & -0.141 & -0.162 & -0.121 \\
& $(0.039) * * *$ & $(0.063) * *$ & $(0.041) * * *$ & $(0.069) *$ \\
log K_s * log K_c & 0.803 & 0.800 & 0.829 & 0.737 \\
& $(0.050) * * *$ & $(0.082) * * *$ & $(0.085) * * *$ & $(0.148) * * *$ \\
log S_s* $*$ log S_c & 0.286 & 0.353 & 0.242 & 0.424 \\
& $(0.041) * * *$ & $(0.065) * * *$ & $(0.040) * * *$ & $(0.062) * * *$ \\
Observations & 22753 & 8235 & 14574 & 5544 \\
R-squared & 0.8041 & 0.8288 & 0.8564 & 0.8667 \\
\hline
\end{tabular}

Notes: Beta coefficients are reported. Country and sector dummies suppressed. Heteroskedasticity robust standard errors in parentheses. ${ }^{*}$ significant at $10 \% ;{ }^{* *}$ significant at $5 \% ; * *$ significant at $1 \%$. All potential country-sector combinations are represented.

Table 7: Pooled Regression - Robustness Checks

\begin{tabular}{|c|c|c|c|c|c|c|c|c|c|c|c|c|}
\hline SIC aggregation & SIC-3 & & SIC-3 & & SIC-3 & & \multicolumn{2}{|l|}{ SIC-3 } & SIC-3 & \multicolumn{3}{|c|}{ SIC-3 } \\
\hline GDPPC cutoff & 2000 & & 5000 & & 2000 & & 5000 & & 2000 & \multicolumn{3}{|c|}{5000} \\
\hline \multirow{2}{*}{ VOL_s $* \log$ FLEX_c } & 0.289 & & 0.374 & & 0.304 & & 0.373 & & 0.246 & & 0.283 & \\
\hline & $(0.073)$ & $* * *$ & $(0.083)$ & $* * *$ & $(0.074)$ & $* * *$ & $(0.084)$ & $* * *$ & $(0.088)$ & $* * *$ & $(0.110)$ & $* * *$ \\
\hline \multirow[t]{2}{*}{$\log \mathrm{K} \_s * \log$ FLEX_c } & -0.297 & & -0.219 & & -0.323 & & -0.218 & & -0.307 & & -0.245 & \\
\hline & $(0.094)$ & $* * *$ & $(0.114)$ & $*$ & $(0.094)$ & $* * *$ & $(0.112)$ & $*$ & $(0.095)$ & $* * *$ & $(0.121)$ & $* *$ \\
\hline \multirow[t]{2}{*}{$\log \mathrm{K} \_s * \log \mathrm{K} \_\mathrm{c}$} & 1.155 & & 1.139 & & 1.165 & & 1.138 & & 1.258 & & 0.177 & \\
\hline & $(0.123)$ & $* * *$ & $(0.236)$ & $* * *$ & $(0.123)$ & $* * *$ & $(0.236)$ & $* * *$ & $(0.541)$ & $* *$ & $(0.745)$ & \\
\hline \multirow[t]{2}{*}{$\log \mathrm{S} \_\mathrm{S} * \log \mathrm{S} \_\mathrm{c}$} & 0.936 & & 0.959 & & 0.938 & & 0.959 & & 0.445 & & 0.299 & \\
\hline & $(0.091)$ & $* * *$ & $(0.102)$ & $* * *$ & $(0.091)$ & $* * *$ & $(0.102)$ & $* * *$ & $(0.148)$ & $* * *$ & $(0.144)$ & $* *$ \\
\hline \multirow[t]{2}{*}{ VOLPROD_AGG_s $* \log$ GDPPC_c } & -0.287 & & -0.238 & & -0.314 & & -0.235 & & -0.274 & & -0.138 & \\
\hline & $(0.097)$ & $* * *$ & $(0.177)$ & & $(0.099)$ & $* * *$ & $(0.193)$ & & $(0.100)$ & $* * *$ & $(0.195)$ & \\
\hline \multirow[t]{2}{*}{ VOL_AGG_s $*$ log FLEX_c } & & & & & 0.124 & & -0.005 & & 0.111 & & -0.031 & \\
\hline & & & & & $(0.102)$ & & $(0.127)$ & & $(0.103)$ & & $(0.128)$ & \\
\hline \multirow[t]{2}{*}{ VOL_s $* \log \mathrm{K} \_\mathrm{c}$} & & & & & & & & & 0.463 & & 1.608 & \\
\hline & & & & & & & & & $(0.434)$ & & $(0.679)$ & $* *$ \\
\hline \multirow[t]{2}{*}{ VOL_s $* \log \mathrm{S} \_\mathrm{c}$} & & & & & & & & & 0.077 & & 0.056 & \\
\hline & & & & & & & & & $(0.077)$ & & $(0.089)$ & \\
\hline \multirow[t]{2}{*}{ VOL_s * log GDPPC_c } & & & & & & & & & -0.344 & & -0.966 & \\
\hline & & & & & & & & & $(0.340)$ & & $(0.546)$ & $*$ \\
\hline \multirow[t]{2}{*}{$\log \mathrm{K} \_s * \log$ GDPPC_c } & & & & & & & & & -0.115 & & 0.720 & \\
\hline & & & & & & & & & $(0.429)$ & & $(0.612)$ & \\
\hline \multirow[t]{2}{*}{$\log \mathrm{S} \_\mathrm{s} * \log$ GDPPC_c } & & & & & & & & & 0.805 & & 1.333 & \\
\hline & & & & & & & & & $(0.170)$ & $* * *$ & $(0.235)$ & $* * *$ \\
\hline Observations & 6513 & & 4675 & & 6513 & & 4675 & & 6513 & & 4675 & \\
\hline R-squared & 0.7487 & & 0.7474 & & 0.7488 & & 0.7474 & & 0.7499 & & 0.7502 & \\
\hline
\end{tabular}

Notes: Beta coefficients are reported. Country and sector dummies suppressed. Heteroskedasticity robust standard errors in parentheses. ${ }^{*}$ significant at $10 \% ; * *$ significant at $5 \% ; * * *$ significant at $1 \%$. 
Table 8: Country-Level Analysis

\begin{tabular}{lcccc}
\hline GDPPC cutoff & 10000 & 5000 & 2000 & NONE (weighted) \\
\hline FLEX_c & 0.820 & 0.574 & 0.292 & 0.275 \\
& $(0.259) * * *$ & $(0.169) * * *$ & $(0.137) * *$ & $(0.109) * *$ \\
GDPPC_c & -0.394 & -0.657 & -0.212 & -0.259 \\
& $(0.412)$ & $(0.428)$ & $(0.361)$ & $(0.183)$ \\
S_c & -0.215 & -0.216 & 0.187 & 0.341 \\
& $(0.207)$ & $(0.205)$ & $(0.208)$ & $(0.178) *$ \\
log K_c & 0.469 & 1.052 & 0.382 & 0.259 \\
& $(0.337)$ & $(0.412) * *$ & $(0.361)$ & $(0.235)$ \\
Observations & 25 & 42 & 61 & 81 \\
R-squared & 0.4728 & 0.4354 & 0.2744 & 0.4690 \\
\hline
\end{tabular}

Notes: Beta coefficients are reported. Standard errors in parentheses. ${ }^{*}$ significant at $10 \%$; ${ }^{* *}$ significant at $5 \%{ }^{* * *}$ significant at $1 \%$. Last column is weighted by RGDP

Table 9: Country-Level Analysis: Correlation between Purged Average Volatility and Country Flexibility

\begin{tabular}{cccccc} 
& OECD & 10000 & 5000 & 2000 & NONE (weighted) \\
\hline & 0.6197 & 0.5511 & 0.4591 & 0.3295 & 0.4918 \\
& $(0.0027)$ & $(0.0013)$ & $(0.0004)$ & $(0.0018)$ & $(0.0000)$ \\
Observations & 21 & 31 & 56 & 87 & 121 \\
\hline
\end{tabular}

Notes: Correlation coefficients are reported. p-values in parentheses. ${ }^{*}$ significant at $10 \% ;{ }^{* *}$ significant at $5 \%{ }^{* * *}$ significant at $1 \%$. Last column is weighted by RGDP 


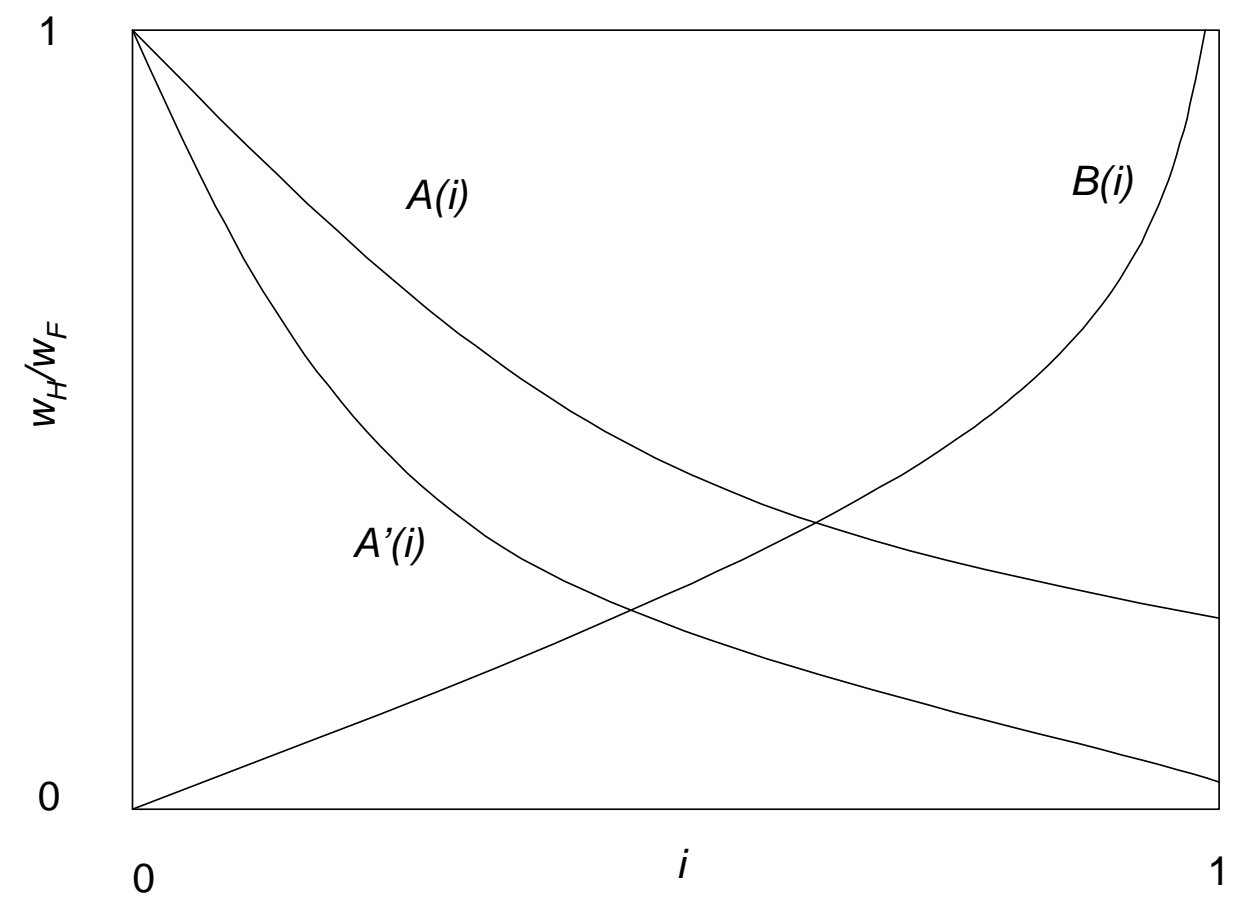

Figure 1: One-factor model: equilibrium and comparative statics

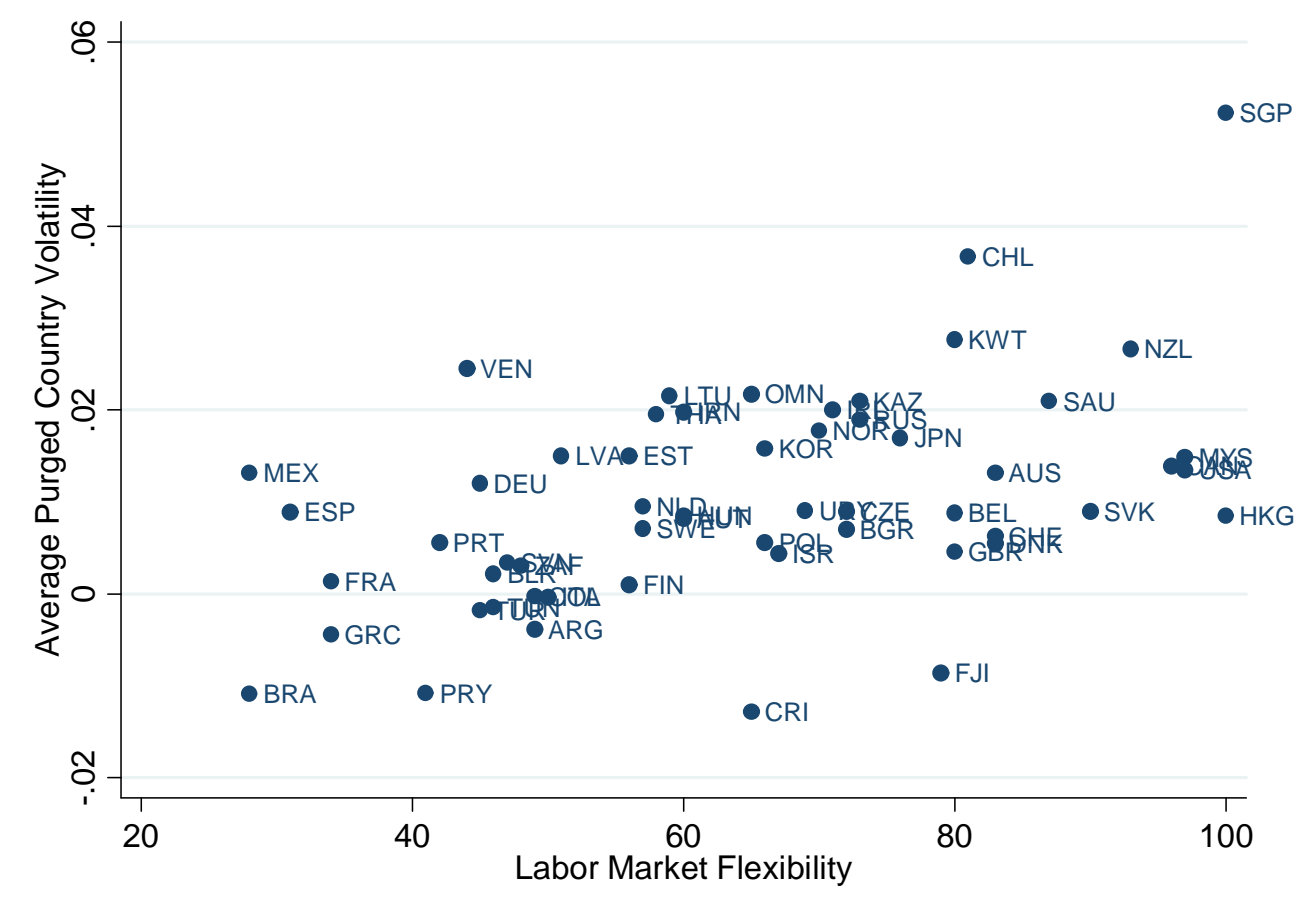

Figure 2: Average volatility and labor market flexibility (GDP per capita $>\$ 5,000$ ) 


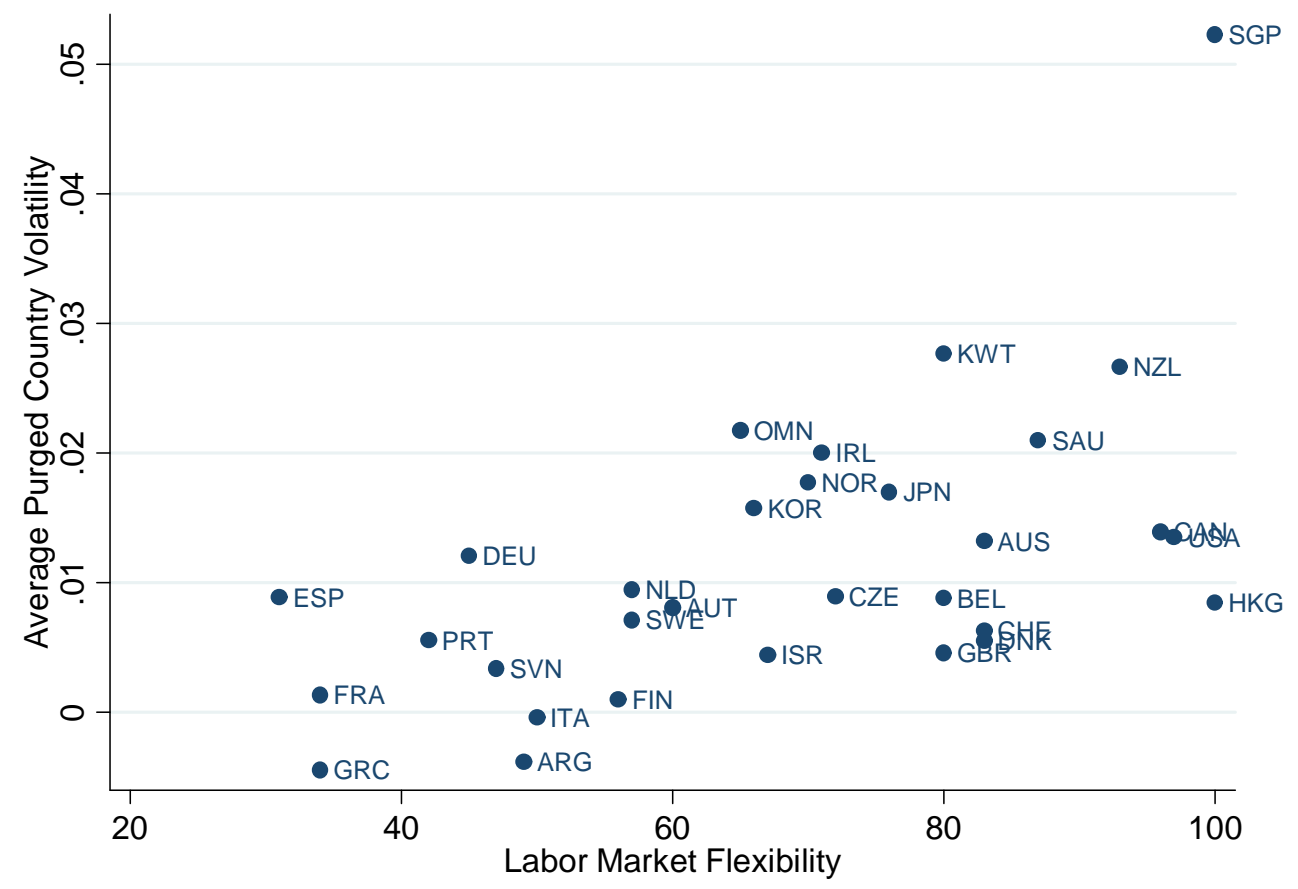

Figure 3: Average volatility and labor market flexibility (GDP per capita $>\$ 10,000$ )

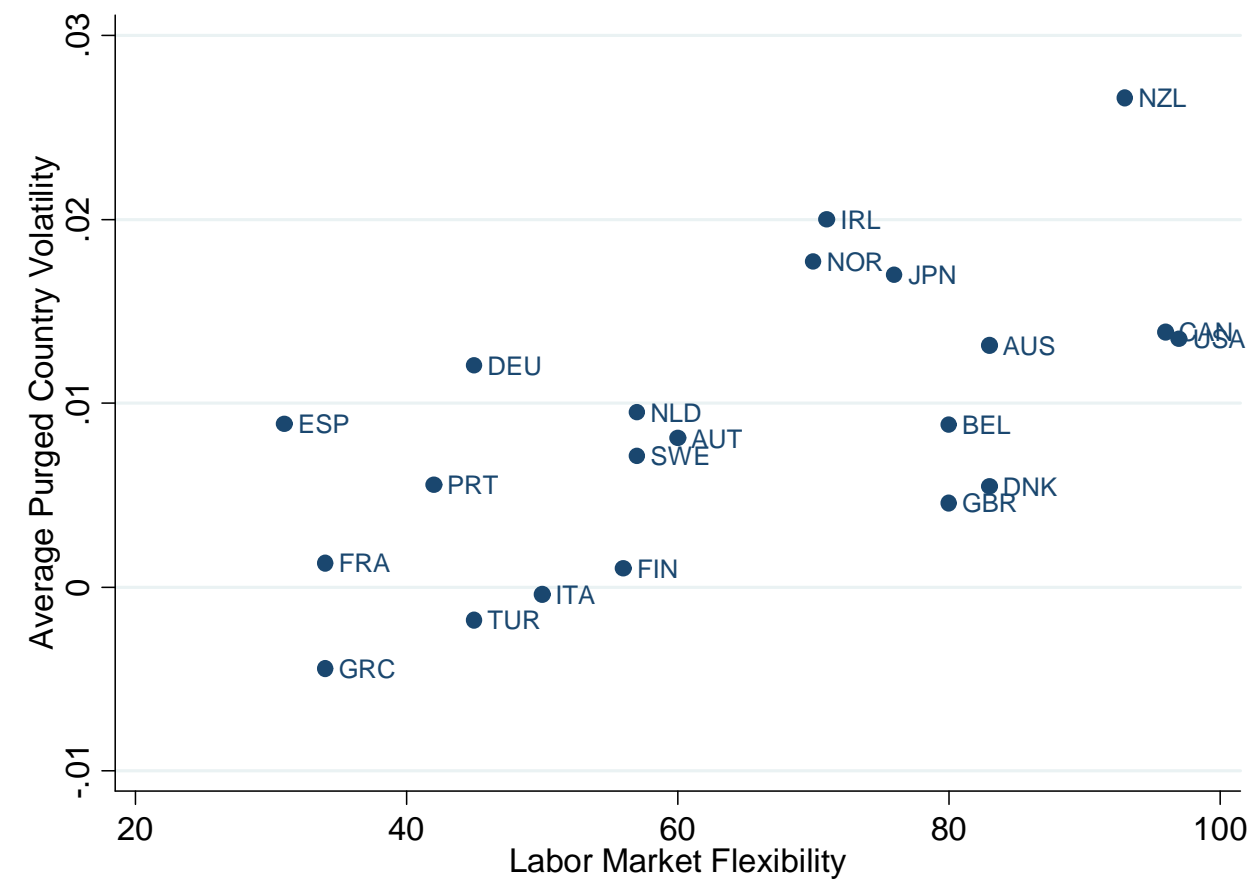

Figure 4: Average volatility and labor market flexibility (OECD countries in 1990s) 


\section{Appendix}

\section{A Two-Factor Model: Autarky in the Flexible Country}

Since the rental rate and the allocation of capital are pre-determined prior to the realization of $\pi$, all intermediate good producers in an industry hire the same amount of capital: $K_{c}(i, \pi)=K_{c}(i), \forall \pi$, where $K_{c}(i)$ is also the total amount of capital hired in the industry (since there is a unit mass of intermediate good producers). ${ }^{31}$ Hence,

$$
\frac{y(\pi)}{y(0)}=e^{\pi}\left[\frac{L(\pi)}{L(0)}\right]^{1-\alpha}
$$

Market clearing for each firm's output $y(\pi)$ and price $p(\pi)$ implies

$$
\frac{y(\pi)}{y(0)}=\left[\frac{p(\pi)}{p(0)}\right]^{-\varepsilon}
$$

Firms hire labor until the value of its marginal product is equal to the common wage:

$$
w=\mu(\alpha) p(\pi)(1-\alpha) e^{\pi} K^{\alpha} L(\pi)^{-\alpha},
$$

where $\mu(\alpha)=\alpha^{-\alpha}(1-\alpha)^{\alpha-1}$. Equations (A.1), (A.2) and (A.3) yield

$$
\frac{p(\pi)}{p(0)}=\exp \left\{\frac{-\pi}{1+\alpha(\varepsilon-1)}\right\}
$$

and

$$
\frac{L(\pi)}{L(0)}=\exp \left\{\frac{(\varepsilon-1)}{1+\alpha(\varepsilon-1)} \pi\right\}
$$

Equations (A.2) and (A.4) imply

$$
\frac{p(\pi) y(\pi)}{p(0) y(0)}=\exp \left\{\frac{(\varepsilon-1)}{1+\alpha(\varepsilon-1)} \pi\right\}
$$

Since labor is paid the value of its marginal product, the Cobb-Douglas production form (and zero profit condition) implies that each firm pays a share $(1-\alpha)$ of its revenue $p(\pi) y(\pi)$ to labor: $w L(\pi)=(1-\alpha) p(\pi) y(\pi)$. This relationship also holds in the aggregate for the industry: $w L=$

\footnotetext{
${ }^{31}$ In what follows, country and industry notation is suppressed for simplicity wherever unnecessary. It is understood that $\alpha$ and $\sigma$ will vary across industries.
} 
$(1-\alpha)$ py. As there are no ex-ante profits, wages are determined so that aggregate capital cost $r K$ equals the remaining $\alpha$ share of revenue:

$$
r K=\alpha \int_{-\infty}^{\infty} p(\pi) y(\pi) d F(\pi)=\alpha p(0) y(0) \exp \left\{\left[\frac{(\varepsilon-1)}{1+\alpha(\varepsilon-1)}\right]^{2} \frac{\sigma^{2}}{2}\right\}
$$

Using expressions $w=\mu(\alpha)(1-\alpha) p(0)[K / L(0)]^{\alpha}$ and $w L(0)=(1-\alpha) p(0) y(0)$, which imply that $p(0) y(0)=[\mu(\alpha)]^{1 / \alpha}[w /(1-\alpha)]^{(\alpha-1) / \alpha} p(0)^{1 / \alpha} K$, equation (A.7) can be written as

$$
r^{\alpha} w^{1-\alpha}=p(0) \exp \left\{\alpha\left[\frac{(\varepsilon-1)}{1+\alpha(\varepsilon-1)}\right]^{2} \frac{\sigma^{2}}{2}\right\}
$$

where the left-hand side is the standard Cobb-Douglas unit cost function. Finally, note that (A.4) implies that the price index for the final good is given by

$$
p=p(0) \exp \left\{-\left[\frac{(\varepsilon-1)}{1+\alpha(\varepsilon-1)}\right]^{2} \frac{1}{\varepsilon-1} \frac{\sigma^{2}}{2}\right\}
$$

Solving out for $p(0)$ using equation (A.8) yields

$$
p=\exp \left\{-\frac{(\varepsilon-1)}{1+\alpha(\varepsilon-1)} \frac{\sigma^{2}}{2}\right\} r^{\alpha} w^{1-\alpha}
$$

One can think of our static set-up as a steady-state equilibrium: the law of large numbers ensures that aggregate outcomes are invariant over time, but the realizations of $\pi$ experienced by an individual firm vary from period to period. Assume $\pi$ is iid over time. From equation (A.6), the growth rate of a firm's sales between periods $t$ and $t^{\prime}$ can be expressed as

$$
\gamma \equiv \log \frac{p\left(\pi^{\prime}\right) y\left(\pi^{\prime}\right)}{p(\pi) y(\pi)}=\frac{(\varepsilon-1)\left(\pi^{\prime}-\pi\right)}{1+\alpha(\varepsilon-1)} .
$$

The standard deviation of $\gamma$ is therefore

$$
\operatorname{vol}_{F}(i, j)=\frac{\sqrt{2}(\varepsilon-1)}{1+\alpha(j)(\varepsilon-1)} \sigma(i)
$$

The one-factor/flexible-country counterpart to equation (A.9) can be obtained by assuming $\alpha(j)=$ 0: $\operatorname{vol}_{F}(i)=\sqrt{2}(\varepsilon-1) \sigma(i)$. Assuming $\alpha(j)=1$ yields the case of a one-factor model in which the factor is 'rigid': $\operatorname{vol}_{F}(i)=\sqrt{2}(\varepsilon-1) \sigma(i) / \varepsilon$. In the two-factor/rigid-country case, we can think 
of the two rigid factors as combining into a composite rigid factor. The prediction for volatility is obviously the same in this case:

$$
\operatorname{vol}_{H}(i, j)=\frac{\sqrt{2}(\varepsilon-1)}{\varepsilon} \sigma(i)<\operatorname{vol}_{F}(i, j)
$$

Not surprisingly, firm sales in the rigid country vary less than in the flexible country, as firms cannot adjust their employment in the rigid country.

\section{B Three Factors}

Assume now that countries use three factors in the production of intermediates: a 'rigid' factor, capital, a 'flexible' factor, materials, and labor. Industries differ in terms of factor intensities and volatility. The Cobb-Douglas aggregate good $Q$ is now defined according to

$$
Q \equiv \exp \left\{\int_{0}^{1} \int_{0}^{1} \int_{0}^{1} \ln q(i, j, m) \operatorname{didj} d m\right\}
$$

where an industry is now characterized by a triple $(i, j, m)$. The final good in each industry is still produced from a C.E.S. continuum of intermediate goods indexed by $z$ :

$$
y(i, j, m)=\left[\int_{0}^{1} y(i, j, m, z)^{\frac{\varepsilon-1}{\varepsilon}} d z\right]^{\frac{\varepsilon}{\varepsilon-1}}
$$

Intermediate goods are now produced with capital, materials, and labor, according to

$$
y(i, j, m, z)=e^{\pi}\left[\frac{K(i, j, m, z)}{\alpha(j)}\right]^{\alpha(j)}\left[\frac{M(i, j, m, z)}{\beta(m)}\right]^{\beta(m)}\left[\frac{L(i, j, m, z)}{1-\alpha(j)-\beta(m)}\right]^{1-\alpha(j)-\beta(m)}
$$

where $\alpha(j), \beta(m), 1-\alpha(j)-\beta(m) \in[0,1]$ are the industry's cost shares of capital, materials, and labor, respectively. As in the one-factor model, the $\pi^{\prime}$ s are iid draws from a common distribution, identical across countries, but different across industries. We maintain the Normal parametrization for the productivity draws $\pi(i) \sim N\left[0, \sigma^{2}(i)\right]$. Labor market flexibility varies across countries in the same way as above. We assume that in both countries, the rental rate and the allocation of capital to intermediate good producers are determined prior to the realization of $\pi$; no adjustment is allowed thereafter. Materials are instead allocated after the realization of $\pi$ in both countries. 


\section{Autarky in the Flexible Country}

This case is similar to the two-factor model with flexible labor and rigid capital: we can rewrite the firm-level production function as

$y(i, j, m, z)=e^{\pi}\left(\frac{K(i, j, m, z)}{\alpha(j)}\right)^{\alpha(j)}\left[\left[\frac{M(i, j, m, z)}{\beta(m)}\right]^{\frac{\beta(m)}{1-\alpha(j)}}\left[\frac{L(i, j, m, z)}{1-\alpha(j)-\beta(m)}\right]^{\frac{1-\alpha(j)-\beta(m)}{1-\alpha(j)}}\right]^{1-\alpha(j)}$

where the term in brackets can be understood as a composite flexible factor, and $K$ as a rigid factor. Therefore,

$$
p_{F}(i, j, m)=\frac{r_{F}^{\alpha(j)} s_{F}^{\beta(m)} w_{F}^{1-\alpha(j)-\beta(m)}}{\tilde{\pi}_{F}(i, j, m)},
$$

where $s$ denotes the price of materials, the numerator is the standard Cobb-Douglas unit cost function, and the industry average productivity level $\tilde{\pi}_{F}(i, j, m)$ is now given by

$$
\tilde{\pi}_{F}(i, j, m)=\exp \left\{\frac{\varepsilon-1}{1+\alpha(j)(\varepsilon-1)} \frac{\sigma^{2}(i)}{2}\right\}
$$

From the two-factor analysis above, we also know

$$
\operatorname{vol}_{F}(i, j, m)=\frac{\sqrt{2}(\varepsilon-1) \sigma(i)}{1+\alpha(j)(\varepsilon-1)}
$$

\section{Autarky in the Rigid Country}

We can rewrite the firm-level production function as

$y(i, j, m, z)=e^{\pi}\left(\frac{M(i, j, m, z)}{\beta(m)}\right)^{\beta(m)}\left[\left[\frac{K(i, j, m, z)}{\alpha(j)}\right]^{\frac{\alpha(j)}{1-\beta(m)}}\left[\frac{L(i, j, m, z)}{1-\alpha(j)-\beta(m)}\right]^{\frac{1-\alpha(j)-\beta(m)}{1-\beta(m)}}\right]^{1-\beta(m)}$,

where the term in brackets can be understood as a composite rigid factor, and $M$ as a flexible factor. Therefore,

$$
p_{H}(i, j, m)=\frac{r_{H}^{\alpha(j)} s_{H}^{\beta(m)} w_{H}^{1-\alpha(j)-\beta(m)}}{\tilde{\pi}_{H}(i, j, m)},
$$

where the industry average productivity level $\tilde{\pi}_{H}(i, j, m)$ is now given by

$$
\tilde{\pi}_{H}(i, j, m)=\exp \left\{\frac{(\varepsilon-1)}{1+[1-\beta(m)](\varepsilon-1)} \frac{\sigma^{2}(i)}{2}\right\}
$$


From the two-factor analysis above, we also know

$$
\operatorname{vol}_{H}(i, j, m)=\frac{\sqrt{2}(\varepsilon-1) \sigma(i)}{1+[1-\beta(m)](\varepsilon-1)} .
$$

\section{The Pattern of Comparative Advantage}

Without loss of generality, we assume that $\beta(m)$ is an increasing and differentiable function of $m$. As in the one-factor and two-factor cases, we can define

$$
A(i, j, m) \equiv \frac{\tilde{\pi}_{H}(i, j, m)}{\tilde{\pi}_{F}(i, j, m)}=\exp \left\{-\frac{(\varepsilon-1)^{2}}{2} \frac{1-\alpha(j)-\beta(m)}{[1+\alpha(j)(\varepsilon-1)][1+[1-\beta(m)](\varepsilon-1)]} \sigma^{2}(i)\right\}
$$

as the ratio of productivity levels for a given industry across the two countries. ${ }^{32}$ This ratio highlights, once again, the absolute productivity advantage of the flexible economy in all sectors: $A(i, j, m)<1, \forall i, j, m$. It also highlights how the pattern of comparative advantage varies with both volatility and factor intensity. $\partial A(i, j, m) / \partial i<0$ as in the one factor case: the productivity advantage is larger in more volatile industries. However, $\partial A(i, j, m) / \partial j>0, \partial A(i, j, m) / \partial m>0$ : holding volatility constant, this productivity advantage is reduced in relatively less labor intensive industries. A smaller labor share share reduces the ability of the flexible economy to take full advantage of the dispersion in productivity levels.

\section{Empirical Measurement of Volatility and Comparative Advantage}

In this section, we show how the same comparative statics for comparative advantage are obtained when they are evaluated in terms of our observed measure of volatility $\operatorname{vol}_{F}(i, j, m)$ : the standard deviation of $\log$ sales across firms in a sector, for an economy with a flexible labor market (the U.S.). ${ }^{33}$ Substituting equation (B.1) into equation (B.2) yields

$$
A(i, j, m)=\exp \left\{-\frac{1}{4} \rho(j, m) v^{2} l_{F}^{2}(i, j, m)\right\}
$$

\footnotetext{
${ }^{32}$ Assuming $\beta(m)=0 \forall m$ brings us back to the two-factor case with 'rigid' capital of section $3 . \quad \alpha(j)=0$ $\forall j$ yields instead the two-factor case with the factor other than labor being 'flexible' in both countries. Finally, $\alpha(j)=\beta(m)=0 \forall j, m$ yields the one-factor model of section 2 .

${ }^{33}$ We note that the same comparative statics would also hold if they were evaluated for a country with a rigid labor market. Choosing the case of a flexible labor market seemed most appropriate since the empirical measure is based on U.S. firms.
} 
where

$$
\rho(j, m)=\frac{[1-\alpha(j)-\beta(m)][1+\alpha(j)(\varepsilon-1)]}{[1+[1-\beta(m)](\varepsilon-1)]}>0 .
$$

Thus, the comparative statics for $A(i, j, m)$ in terms of $\operatorname{vol}_{F}$ are identical to those in terms of $\sigma^{2}(i)$ : relative productivity $A(i, j, m)$ varies negatively with volatility for both measures. We now turn to the secondary effect of labor market flexibility based on variations in factor intensities. Some tedious algebra yields

$$
\begin{aligned}
& \frac{\partial \rho[\alpha(j), \beta(m)]}{\partial \alpha(j)}=\frac{(\varepsilon-1)[1-2 \alpha(j)-\beta(m)]-1}{[(1-\beta(m)) \varepsilon+\beta(m)]}, \\
& \frac{\partial \rho[\alpha(j), \beta(m)]}{\partial \beta(m)}=-\left[\frac{\alpha(j) \varepsilon+1-\alpha(j)}{(1-\beta(m)) \varepsilon+\beta(m)}\right]^{2} .
\end{aligned}
$$

Clearly, $\partial \rho[\alpha(j), \beta(m)] / \partial \beta(m)<0$. Although the sign of $\partial \rho[\alpha(j), \beta(m)] / \partial \alpha(j)$ is analytically ambiguous, we document that this derivative is negative for virtually all empirical measures of $\alpha(j)$ and $\beta(m)$ across sectors, combined with plausible values for $\varepsilon . \partial \rho[\alpha(j), \beta(m)] / \partial \alpha(j)<0$ if and only if

$$
2 \alpha(j)+\beta(m)>\frac{\varepsilon-2}{\varepsilon-1} .
$$

The RHS of (B.3) is increasing in $\varepsilon$. Even for an upper-bound value for $\varepsilon$ of 10, the RHS is below $.9 .^{34}$ We can evaluate the empirical distribution of the LHS of (B.3) across all U.S. SIC sectors that we use in our empirical analysis. We use expenditures on energy and materials as a share of the gross value of production to represent $\beta(m)$. We compute a similar share for expenditures on labor, and compute $\alpha(j)$ as the residual share, 1 minus the sum of the other shares (labor and $\beta(m))$. At the SIC-3 level, the LHS for all sectors is bounded below by .9. At the SIC-4 level, $98 \%$ of sectors have a LHS value above .9. Thus, empirically, (B.3) will be satisfied for all SIC-3 sectors and almost all the SIC-4 sectors. We therefore conclude that our secondary comparative statics also hold when evaluated in terms of our empirical measure of volatility, $\operatorname{vol}_{F}$.

\section{Degrees of Flexibility/Rigidity}

A simple way of introducing different degrees of labor market flexibility/rigidity is to assume that each industry is comprised of both flexible and rigid sub-industries - henceforth sectors - and thus

\footnotetext{
${ }^{34}$ Virtually all micro-level studies measuring elasticities of substitution (or cross-price elasticities) within sectors find estimates substantially below 10 (except for very rare cases of a few special commodity goods). One of the most comprehensive such study, using data on prices across export origins by Broda and Weinstein (2006), finds a median price elasticity of 2.5 within all traded 3-digit SITC sectors (the standard error across the 327 different sectors is 1.2 ).
} 
introducing one additional layer of aggregation into the model. For simplicity, we will work out the one-factor case. The extension to the many-factor case is immediate.

We maintain most of our assumptions from the main text. We now think of each industry $i$ as an aggregate of nontraded sectors $s$ :

$$
y(i)=\exp \left\{\int_{0}^{1} \ln y(i, s) d s\right\}
$$

where $y(i)$ denotes production of final good $i$. Each good $s$ is produced with a continuum of nontraded intermediate goods:

$$
y(i, s)=\left[\int_{0}^{1} y(i, s, z)^{\frac{\varepsilon-1}{\varepsilon}} d z\right]^{\frac{\varepsilon}{\varepsilon-1}} .
$$

Each intermediate good is produced with labor $y(i, s, z)=e^{\pi} L(i, s, z)$. An economy-wide wage $w$ is chosen before uncertainty is realized. We assume that the unemployed cannot bid down this wage. Within each industry, there are 'flexible' and 'rigid' sectors. We assume that a measure $\lambda \in[0,1]$ of sectors in industry $i$ are flexible, whereas a measure $(1-\lambda)$ are rigid. Labor is ex-ante perfectly mobile across sectors and industries.

In a flexible sector, firms hire labor after uncertainty is realized. After the realization of $\pi$, production and commodity market clearing take place in a competitive setting. Rigid sectors must hire labor before uncertainty is realized, and the intermediate good producer is contractually committed to paying the hired number of workers the negotiated wage (regardless of the realization of $\pi$ ). After the realization of $\pi$, production and commodity market clearing take place in a competitive setting, subject to the wage and employment restrictions. Rigid-sector intermediate goods producers anticipate this equilibrium, and adjust their contracted labor demand accordingly. Given ex-ante free entry into the intermediate goods sector, expected profits of the rigid-sector intermediate good producers are driven to zero.

\section{Autarky}

For $s \in[0, \lambda]$,

$$
\tilde{\pi}(i, s)=\left[\int_{-\infty}^{\infty} e^{(\varepsilon-1) \pi} d G_{i}(\pi)\right]^{\frac{1}{\varepsilon-1}}
$$


whereas for $s \in[\lambda, 1]$,

$$
\tilde{\pi}(i, s)=\left[\int_{-\infty}^{\infty} e^{\frac{(\varepsilon-1)}{\varepsilon} \pi} d G_{i}(\pi)\right]^{\frac{\varepsilon}{\varepsilon-1}} .
$$

In both cases, $p(i, s)=w / \tilde{\pi}(i, s)$. Given the absolute advantage of flexible sectors over rigid sectors, an industry's price index is a negative function of $\lambda$. Assuming $\pi \sim N\left(0, \sigma^{2}\right)$, the industry's price index is $p(i)=w / \tilde{\pi}(i)$, where

$$
\tilde{\pi}(i)=\exp \left\{\left[\frac{(\varepsilon-1)^{2}}{\varepsilon} \lambda+\frac{(\varepsilon-1)}{\varepsilon}\right] \frac{\sigma^{2}(i)}{2}\right\}
$$

is the combined productivity average for industry $i$.

\section{Free Trade}

Assume $\lambda_{F}>\lambda_{H}$. Define

$$
A(i) \equiv \frac{\tilde{\pi}_{H}(i)}{\tilde{\pi}_{F}(i)}=\exp \left\{-\frac{(\varepsilon-1)^{2}}{2 \varepsilon}\left(\lambda_{F}-\lambda_{H}\right) \sigma^{2}(i)\right\}
$$

As in the one-factor model in the main text, the full-employment free-trade equilibrium can be characterized by the intersection of $A(i)$ and $B(i)$. Notice that an increase in $\lambda_{F}-\lambda_{H}$ will have effects similar to a proportional increase in $\sigma^{2}(i)$ for all $i$. (In other words, $\lambda_{F}-\lambda_{H}$ operates like $\psi$.)

Consider now the case with unemployment, and again normalize $w_{F}=1$. The condition $w_{H}=$ $A(\bar{\imath})$ still determines the equilibrium specialization pattern: $\bar{\imath}=\bar{\imath}\left(w_{H}, \lambda_{F}-\lambda_{H}\right)$. Again, since $\partial A(\cdot) / \partial i<0, d \bar{\imath} / d w_{H}<0$. Goods market clearing requires $w_{H} L_{H} / L_{F}=$ $\bar{\imath}\left(w_{H}, \lambda_{F}-\lambda_{H}\right) /\left[1-\bar{\imath}\left(w_{H}, \lambda_{F}-\lambda_{H}\right)\right] \equiv B\left(w_{H}, \lambda_{F}-\lambda_{H}\right)$, where $B(\cdot)$ depends negatively on $w_{H}$. It is easy to see that country $H$ 's employment level (relative to country $F$ 's) depends negatively on $w_{H}: L_{H} / L_{F}=B\left(w_{H}, \lambda_{F}-\lambda_{H}\right) / w_{H}, \partial\left(L_{H} / L_{F}\right) / \partial w_{H}<0$. Finally, an increase in $\lambda_{F}-\lambda_{H}$ (or a proportional increase in $\sigma^{2}(i)$ for all $i$ ) will shift $L_{H} / L_{F}$ down for a given $w_{H}$ : $\partial\left(L_{H} / L_{F}\right) / \partial\left(\lambda_{F}-\lambda_{H}\right)<0$. 


\section{CENTRE FOR ECONOMIC PERFORMANCE Recent Discussion Papers}

798 Giulia Faggio

797 Nicholas Oulton

796 David Marsden Richard Belfield Salima Benhamou

795 Andrew B. Bernard J. Bradford Jensen Stephen Redding Peter K. Schott

794 Richard E. Baldwin Frédéric Robert-Nicoud

793 Alan Manning

792 Nick Bloom

791 Richard E. Baldwin Frédéric Robert-Nicoud

790 Alan Manning Sanchari Roy

789 Giorgio Gobbi Roberta Zizza

788 Nick Bloom Raffaella Sadun John Van Reenen

787 Elizabeth O. Ananat Guy Michaels

786 Willem H. Buiter

785 Gustavo Crespi Chiara Criscuolo Jonathan E. Haskel Matthew Slaughter

784 Richard Layard Guy Mayraz Stephen Nickell
Job Destruction, Job Creation and Unemployment in Transition Countries: What Can We Learn?

Chain Indices of the Cost of Living and the PathDependence Problem: an Empirical Solution

Inventive Pay Systems and the Management of Human Resources in France and Great Britain

Firms in International Trade

Offshoring: General Equilibrium Effects on Wages, Production and Trade

Respect

Uncertainty and the Dynamics of R\&D

Entry and Asymmetric Lobbying: Why

Governments Pick Losers

Culture Clash or Culture Club? The Identity and Attitudes of Immigrants in Britain

Does the Underground Economy Hold Back Financial Deepening? Evidence from the Italian Credit Market

Americans do I.T. better: US Multinationals and the Productivity Miracle

The Effect of Marital Breakup on the Income Distribution of Women with Children

Seigniorage

Productivity Growth, Knowledge Flows and Spillovers

The Marginal Utility of Income 
783 Gustavo Crespi Chiara Criscuolo Jonathan E. Haskel

782 Paul Castillo Carlos Montoro

Vicente Tuesta

781 David Metcalf

780 Carlos Montoro

779 Sharon Belenzon Mark Schankerman

778 Henry G. Overman Diego Puga Matthew A. Turner

777 Florence Kondylis

776 Willem H. Buiter

775 Francesco Caselli Nicola Gennaioli

774 Paul Willman Alex Bryson

773 Alan Manning

772 Guy Michaels

771 Gianluca Benigno Christoph Thoenissen

770 Michael Smart Daniel M. Sturm

769 Andrew B. Bernard Stephen J. Redding Peter K. Schott
Information Technology, Organisational Change and Productivity Growth: Evidence from UK Firms

Inflation Premium and Oil Price Volatility

Why Has the British National Minimum Wage Had Little or No Impact on Employment?

Monetary Policy Committees and Interest Rate Smoothing

Harnessing Success: Determinants of University Technology Licensing Performance

Decomposing the Growth in Residential Land in the United States

Conflict-Induced Displacement and Labour Market Outcomes: Evidence from Post-War Bosnia and Herzegovina

Is Numérairology the Future of Monetary Economics? Unbundling numéraire and medium of exchange through a virtual currency and a shadow exchange rate

Economics and Politics of Alternative Institutional Reforms

Union Organization in Great Britain Prepared for symposium for the Journal of Labor Research on "The State of Unions: A Global Perspective"

The Plant Size-Effect: Agglomeration and Monopsony in Labour Markets

The Effect of Trade on the Demand for Skill Evidence from the Interstate Highway System

Consumption and Real Exchange Rates with Incomplete Markets and Non-Traded Goods

Term Limits and Electoral Accountability

Multi-Product Firms and Trade Liberalization

The Centre for Economic Performance Publications Unit Tel 02079557673 Fax 02079557595 Email info@cep.lse.ac.uk Web site http://cep.lse.ac.uk 